\title{
Application of Stem Cell-Derived Extracellular Vesicles as an Innovative Theranostics in Microbial Diseases
}

\author{
Hani Keshavarz Alikhani', Bahare Shokoohian', Sama Rezasoltani', \\ Nikoo Hossein-khannazer ${ }^{3}$, Abbas Yadegar ${ }^{2}$, Moustapha Hassan ${ }^{4}$ and \\ Massoud Vosough ${ }^{1,4 *}$
}

\section{OPEN ACCESS}

Edited by:

Amin Tamadon,

PerciaVista R\&D Co., Iran

Reviewed by:

Mahdi Mahdipour,

Tabriz University of Medical Sciences,

Nur Izzah Ismail,

The Chinese University of Hong Kong,

Hong Kong SAR, China

Jafar Rezaie,

Urmia University of Medical Sciences,

Iran

*Correspondence:

Massoud Vosough

masvos@Royaninstitute.org

Specialty section:

This article was submitted to

Antimicrobials, Resistance

and Chemotherapy,

a section of the journal

Frontiers in Microbiology

Received: 29 September 2021 Accepted: 11 November 2021 Published: 30 November 2021

Citation:

Keshavarz Alikhani $\mathrm{H}$,

Shokoohian B, Rezasoltani S, Hossein-khannazer N, Yadegar A, Hassan M and Vosough M (2021) Application of Stem Cell-Derived Extracellular Vesicles as an Innovative

Theranostics in Microbial Diseases.

Front. Microbiol. 12:785856 doi: 10.3389/fmicb.2021.785856
${ }^{1}$ Department of Regenerative Medicine, Cell Science Research Center, Royan Institute for Stem Cell Biology and Technology, Academic Center for Education, Culture and Research, Tehran, Iran, ${ }^{2}$ Foodborne and Waterborne Diseases Research Center, Research Institute for Gastroenterology and Liver Diseases, Shahid Beheshti University of Medical Sciences, Tehran, Iran, ${ }^{3}$ Gastroenterology and Liver Diseases Research Center, Research Institute for Gastroenterology and Liver Diseases, Shahid Beheshti University of Medical Sciences, Tehran, Iran, ${ }^{4}$ Experimental Cancer Medicine, Institution for Laboratory Medicine, Karolinska Institute, Stockholm, Sweden

Extracellular vesicles (EVs), as nano-/micro-scale vehicles, are membranous particles containing various cargoes including peptides, proteins, different types of RNAs and other nucleic acids, and lipids. These vesicles are produced by all cell types, in which stem cells are a potent source for them. Stem cell-derived EVs could be promising platforms for treatment of infectious diseases and early diagnosis. Infectious diseases are responsible for more than 11 million deaths annually. Highly transmissible nature of some microbes, such as newly emerged severe acute respiratory syndrome coronavirus 2 (SARS-CoV-2), drives researcher's interest to set up different strategies to develop novel therapeutic strategies. Recently, EVs-based diagnostic and therapeutic approaches have been launched and gaining momentum very fast. The efficiency of stem cell-derived EVs on treatment of clinical complications of different viruses and bacteria, such as SARS-CoV-2, hepatitis B virus (HBV), hepatitis C virus (HCV), human immunodeficiency virus (HIV), Staphylococcus aureus, Escherichia coli has been demonstrated. On the other hand, microbial pathogens are able to incorporate their components into their EVs. The microbe-derived EVs have different physiological and pathological impacts on the other organisms. In this review, we briefly discussed biogenesis and the fate of EVs. Then, EV-based therapy was described and recent developments in understanding the potential application of stem cell-derived EVs on pathogenic microorganisms were recapitulated. Furthermore, the mechanisms by which EVs were exploited to fight against infectious diseases were highlighted. Finally, the deriver challenges in translation of stem cell-derived EVs into the clinical arena were explored.

Keywords: stem cells, infectious disease, antimicrobial agents, bacterial EVs, Viral EVs, MSC-derived EVs, extracellular vesicles 


\section{INTRODUCTION}

\section{What Are the Extracellular Vesicles?}

Extracellular vesicles as "pro-coagulant dust" were identified by Wolf from blood platelets in Wolf (1967), and then in Pan and Johnstone (1983) were among the first scientists who described EVs (Pan and Johnstone, 1983). EVs are a heterogeneous group of vesicles containing different cargos (Abels and Breakefield, 2016). They can transfer different biomolecules such as lipids, proteins, and nucleic acids between different cells, distinguishing their significant role in cell-cell communications (Raposo and Stoorvogel, 2013). EVs are generated and released by almost all types of cells and are classified as exosomes, macrovesicles, and apoptotic bodies (Gurunathan et al., 2021; Pournaghi et al., 2021). Also, ectosomes, shedding vesicles, and microparticles are other types of EVs involved in inter/intra cellular communications (Gurunathan et al., 2019). EVs have attracted tremendous attention from both basic and clinical fields of study during the last decade due to their putative and significant role in several physiological and pathological processes (Jadli et al., 2020). EVs have been isolated from different body fluids such as blood, urine, tears, saliva, etc. (Akers et al., 2013). Some disorders such as inflammatory diseases can modify the EVs and change their numbers, content, composition, and function (Knijff-Dutmer et al., 2002). It has been shown that microbial infections can change the production and release process of EVs in infected cells (Rodrigues et al., 2018). Moreover, some EVs derived from immune cells can play a key role in induction of inflammation (Spencer and Yeruva, 2021).

\section{Types of Extracellular Vesicles}

Macrovesicles (MVs), also known as microparticles, are small membranous vesicles released from almost all cell types including mesenchymal stem cells, endothelial cells, some immune cells, etc. (Cocucci et al., 2009). Their size is ranging from 100 to $1000 \mathrm{~nm}$, and they are formed by direct outward blebbing and pinching of the cell membrane. The production of EVs is regulated by physiological and/or pathological processes (Lynch and Ludlam, 2007; Sedgwick and D'Souza-Schorey, 2018). Initially, MVs are considered as cell debris, however, they recently were recognized as mediators of inter/intra cellular communication tools (Camussi et al., 2010). MVs can carry various bioactive molecules such as cytokines and chemokines, which highlight their antimicrobial potential and also their role in host defense against pathogenic microorganisms (Timár et al., 2013).

Apoptotic cell-derived EVs (ApoEVs) are another class of EVs released from apoptotic cells and contain cell organelles and nuclear materials (Gurunathan et al., 2019). ApoEVs are divided into two subtypes, including large apoptotic bodies (ApoBDs) with a diameter range of 1000-5000 $\mathrm{nm}$ and small apoptotic microvesicles (ApoMVs) with $<1000 \mathrm{~nm}$ (Caruso and Poon, 2018). ApoEVs are important because they accelerate apoptotic cell clearance and also have a role in intercellular communication and immune modulation (Zitvogel et al., 2010; Poon et al., 2014).
ApoEVs act as a key regulator of antigen presentation process, antimicrobial immunity against pathogens, and modulator of the dendritic cells' response against viral infections (Winau et al., 2006; Schiller et al., 2008; Caruso and Poon, 2018).

Exosomes (30-150 $\mathrm{nm}$ in diameter) are the third group of EVs isolated from a variety of body fluids and released by the fusion of multivesicular bodies (MVBs) with the plasma membrane (Simons and Raposo, 2009; Babaei and Rezaie, 2021; Mobarak et al., 2021). Some exosomes are generated and released from various cells in response to different stimuli, but others are continuously produced and released (Mathivanan et al., 2010). They contain various types of cargo molecules which are engaged in the biogenesis and transportation ability of exosomes (Zhang et al., 2019). Exosomes have been implicated in a variety of biological functions, including elimination of old and disused biomolecules (Harding et al., 2013), involvement in tumor progression especially in angiogenesis and metastases (Rak, 2010; Hood et al., 2011), antigen presentation (Bobrie et al., 2011), differentiation of some immune cells to modulate immune responses (Zhang and Grizzle, 2011), and facilitating the spread of some pathogenic microbes or elimination of microbes through interaction with recipient cells (Furuyama and Sircili, 2021; White et al., 2021).

\section{Isolation Methods of Extracellular Vesicles}

Several isolation methods are currently developed for the isolation and purification of EVs in bulk (Witwer et al., 2013). Sequential centrifugation and ultracentrifugation are the conventional methods to isolate EVs in cell culture media or body fluids (Théry et al., 2006). Gradient ultracentrifugation based on sucrose density is also used to minimize protein contamination (Tauro et al., 2012). Chromatography is another tool that can be employed to purify exosomes based on their size and dimensions or surface markers such as CD9, CD63, CD81, and EpCAM (Böing et al., 2014; Oksvold et al., 2015). Once isolated, the purified EVs are characterized. Currently, several methods are developed to analyze the EVs and their content for both research and clinical purposes. These methods include transmission and scanning electron microscopy (TEM and SEM), atomic force microscopy (AFM), dynamic light scattering (DLS), nanoparticle tracking analysis (NTA), resistive pulse sensing (RPS), flow cytometry, fluorescence-activated cell sorting (FACS), enzyme-linked immunosorbent assay (ELISA), microfluidics, and electrochemical biosensor-based devices (Théry et al., 2006; Woo et al., 2016).

\section{Contents of Extracellular Vesicles}

The content, or cargo, of EVs varies and extremely depends on the parental cells and recently new databases including ExoCarta, Vesiclepedia, exoRBase, EVmiRNA, and EV pedia were developed to classify them (Liu et al., 2019). These databases provide information about the content of EVs such as lipids, proteins, miRNAs, and other components. Also they provide useful information about the isolation and characterization of 
EVs (Jadli et al., 2020). The proteome of the EVs is affected by their biogenesis. For example, ESCRT proteins (Alix, TSG101, HSC70, and HSP90 $\beta$ ) regulate the biogenesis and transportation of some EVs and thus these proteins are expected to be found in EVs regardless of the type of the originating cells (Théry et al., 2001; Van Niel et al., 2006). Therefore these proteins can be used as marker for the detection and characterization of EVs (Doyle and Wang, 2019). Some tetraspanin families of proteins such as CD63, CD9, and CD81 are commonly found in EVs and also used as marker proteins both for the detection and purification of EVs (Witwer et al., 2013). Along with the exosome and some EVs surface markers, EVs carry certain biomolecules such as mRNA, miRNA (Zhou J. et al., 2013), cytokines, and antigen presentation molecules (MHC-I, MHC-II) (Gutiérrez-Vázquez et al., 2013) which contribute to the physiological and pathological function of exosomes (Dini et al., 2020). Microbial EVs contain different cargoes based on their origin. The EVs of Gram-negative bacteria contain cytoplasmic proteins, nucleic acids, virulence factors (e.g., toxins), peptidoglycan, and inner membrane. The EVs of Gram-positive bacteria contain membrane-associated virulence proteins, fatty acids, lipoteichoic acid, phospholipids, and some components similar to the Gram-negative EVs (Yu et al., 2018; Bose et al., 2020).

\section{Common Uses of Extracellular Vesicles}

As mentioned above, EVs are mainly responsible for inter/intracellular communications. It was shown that EVs could interact with target cells and therefore they make an impact on cell physiology, phenotype, and function (Simons and Raposo, 2009; Mardpour et al., 2018). Also they can mediate the horizontal transfer of genetic materials (Natasha et al., 2014). Due to the widespread and cell-specific availability of some types of EVs, particularly exosomes, in almost all body fluids, they can be considered as biomarkers (Zhang et al., 2019). Moreover, EVs can be used as delivery vehicles for the efficient transfer of biological therapeutic agents across different biological barriers to desired cells (Haney et al., 2015). In addition, EVs can be applied in regenerative medicine, tissue engineering and cell homeostasis (Gurunathan et al., 2021). They play critical roles in immunoregulation, including antigen presentation, immune activation, immune suppression, and also immune tolerance via exosome-mediated inter/intracellular communications. They also play pivotal role in the host defense against viral and microbial infections (Gurunathan et al., 2021). Documented evidence has shown that host cellsderived EVs and even EVs derived from bacteria can mediate the crosstalk between pathogen and innate immune cells, and thus modulate the innate immune responses of the host (Munich et al., 2012).

In this review article, we first discussed the biogenesis and the fate of EVs. Then, EV-based therapy was described and recent developments in understanding the potential application of stem cell-derived EVs in infectious diseases were recapitulated. In addition, the mechanisms by which EVs were exploited to fight against infectious diseases were highlighted. Finally, the deriver challenges that exists in the translation of stem cell-derived EVs into the clinical arena were explored.

\section{BIOGENESIS AND THE FATE OF EXTRACELLULAR VESICLES}

\section{Biogenesis}

The biogenesis of the exosomes is well-defined as compared to the other types of EVs. The biogenesis of exosomes is a multistep biological process regulated through different signaling pathways (Abels and Breakefield, 2016). Biogenesis of exosomes initiates with the formation of early endosomes followed by second inward budding of the endosomal membrane which leads to the formation of the late endosomes. Late endosomes or intraluminal vesicles (ILVs) follow the endocytic pathway for the generation of exosomes (Sluijter et al., 2014). In the final stage, the generated ILVs are released as exosomes into the extracellular space via exocytosis (Jadli et al., 2020). Some endogenous molecules such as small GTPase Ral (Hyenne et al., 2018) and adiponectin/T-cadherin (Obata et al., 2018) and also some microbes including viral infections and Gram-positive and Gram-negative bacterial infections as extrinsic factors can influence the biogenesis of exosomes (Crenshaw et al., 2018). For the biogenesis of exosomes, different protein sorting mechanisms have been identified, among them endosomal sorting complex transport (ESCRT)-dependent pathway (Frankel and Audhya, 2018) and ESCRT-independent pathway (Babst, 2011) are two widely explained mechanisms (Figure 1).

\section{Endosomal Sorting Complex Transport-Dependent Mechanism}

The ESCRT-dependent mechanism is well-characterized and comprised of many proteins arranged into four proteins complexes including ESCRT-0, -I, -II, and -III. Some proteins such as VPS4, VTA1, and ALIX are associated with these protein complexes. The ESCRT-dependant exosome biogenesis is initiated by recognition and sequestration of ubiquitinated proteins via ubiquitin-binding subunits of ESCRT-0. Then, the ESCRT-0 interacts with the ESCRT-I and -II complexes and all of them will combine with ESCRT-III, a protein complex that is contributed to enhance budding processes. Finally, following cleaving the buds to form ILVs, the ESCRT-III complex disassociates from the MVB membrane with energy supplied by the sorting protein Vps4 (Ren et al., 2008).

\section{Endosomal Sorting Complex Transport-Independent Mechanism}

While ESCRT pathway is the most important mechanism for exosome formation, some EVs such as MBV and ILV are also formed in an ubiquitin-independent way called CRTindependent pathways (Babst, 2011). Heparan sulfate promotes exosome biogenesis through syntenin. Syntenin serves as an intermediate between ESCRT-I and ESCRT-III and is involved in the budding processes (Addi, 2019). Another ESCRT-independent exosome formation was described in the oligodendroglial cells. These cells secret exosomes containing proteolipid protein (PLP) which depends on the depletion of neutral sphingomyelinases (nSMase). Furthermore, tetraspaninenriched microdomains (TEMs) full of CD81 particles are 
A

Eukaryotic cells (MSC)

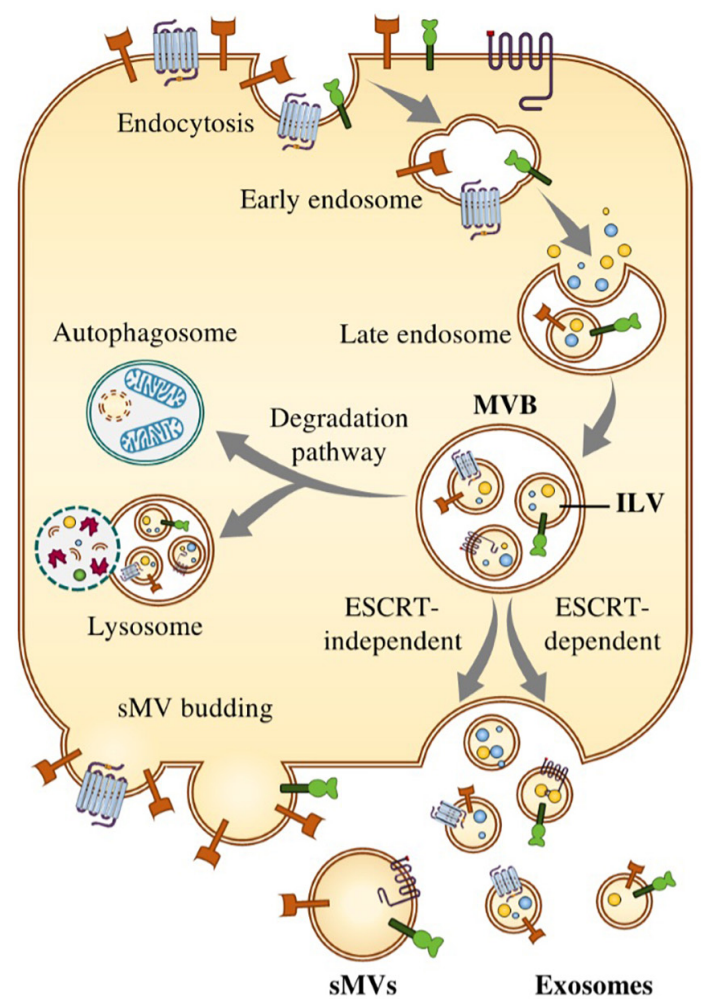

B Gram-negative bacteria

Gram-positive bacteria

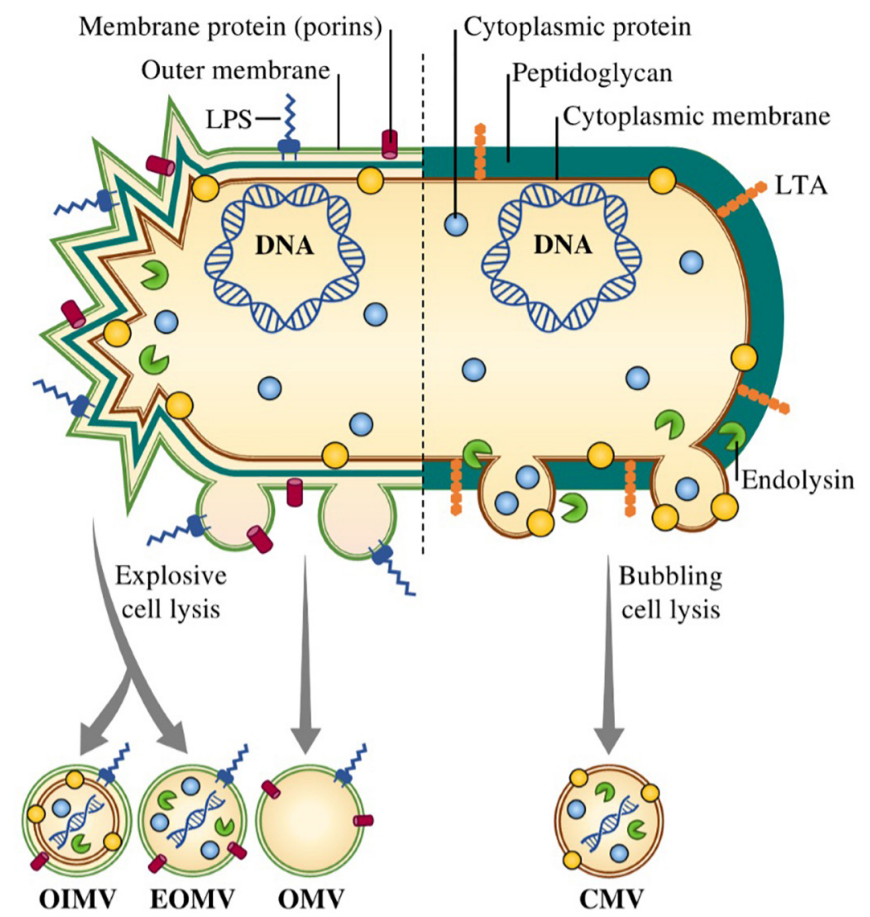

FIGURE 1 | Biogenesis of Extracellular vesicles (EVs) in eukaryotic cells and Gram-negative and -positive bacteria. (A) In eukaryotic cells, biogenesis of EVs consists of three consecutive steps, including (i) formation of early endosome by invagination of the plasma membrane; (ii) formation of late endosome and then MVBs; and finally (iii) fusion of MVBs with the plasma membrane and release of the vesicular contents by ESCRT-dependent and -independent mechanisms. (B) In the Gram-negative bacterial extracellular vesicles, known as outer membrane vesicles mainly originate from the outer membrane of bacterial envelope. Three potential biogenesis mechanisms have been suggested including the blebbing of the outer membrane of the bacterial envelope (OMVs), the formation of outer-inner membrane vesicles (OIMVs) and the formation of explosive outer membrane vesicles (EOMVs). Gram-positive bacteria (B) lack an outer membrane and also have a thick peptidoglycan cell wall outside of the cell membrane which convey the assumption that membrane-derived vesicles could not escape such large barriers but EVs may be forced through the wall by turgor pressure after release from the plasma membrane. In addition, cell wall-modifying enzymes facilitate the released of EVs.

regarded to be another ESCRT-independent pathway of protein sorting into ILVs (Garín et al., 2007).

\section{Extracellular Vesicles Secretion}

To release exosomes, multiple cellular steps are required to be completed including formation of MVBs, transportation of MVBs to the plasma membrane, and fusion of MVBs with the plasma membrane. Several molecules have been engaged in these processes (Rabinovich et al., 2000). MVB can either fuse with a lysosome to degrade their cargo or fuse with the plasma membrane, leading to exosome release. ISGylation, a posttranslational ubiquitin-like modification, is one of the signals that regulates the MVBs' fate. ISGylation of MVB proteins promotes fusion of MVBs with lysosomes, which promoting the exosome release (Chen et al., 2003).

\section{Mechanisms of Exosome Uptake}

Following the release and secretion of EVs to the extracellular environment, the EVs' ability to interact with recipient cells and capacity to deliver their contents such as proteins, lipids, and nucleic acids into the recipient cells can determine the role of EVs in physiological and pathological processes (Jadli et al., 2020). Several mechanisms have been introduced for the uptake of exosomes, including phagocytosis, macropinocytosis, clathrinmediated endocytosis (CME), caveolin-dependent endocytosis (CDE), and plasma membrane fusion (Tamura et al., 2016; Sun et al., 2018). Phagocytosis is in charge of the internalization of bacteria, EVs, and others components. Toll-like receptors (TLRs), scavenger, and complement receptors, as specific targets on the cell surface, participate in invaginations around the material intended for internalization (Wei et al., 2021). Macropinocytosis is another mechanism characterized by plasma membrane ruffling and is induced by growth factors or other signal stimulations. Membrane ruffles form a cup-like structure that seals at its distal tips to construct a relatively large endosome (Canton, 2018). The resulting vesicles contain extracellular fluid and small particles (Wei et al., 2021). CME is a receptormediated endocytic process used to transport a wide range of 
cargo molecules from the cell surface to the interior. Clathrin and adaptor protein 2 (AP2) complexes are necessary for the formation of clathrin-coated vesicles and then the internalization of cargo molecules (Palmirotta et al., 2018). CDE requires the caveolin, a dimeric protein, in the plasma membrane to facilitate the raft-mediated endocytosis (Melo et al., 2015). CDE is another mechanism for the uptake of EVs, but the precise mechanism of internalization may differ depending on the type of EVs and recipient cells (Nanbo et al., 2013). Fusion is the last mechanism of EVs internalization, which enables EVs membrane to directly merge with the cell plasma membrane and transfer cargo molecules to recipient cells (Jadli et al., 2020).

\section{EXTRACELLULAR VESICLES-BASED THERAPY OF MICROBIAL DISEASES}

\section{Role of Extracellular Vesicles in Bacterial and Viral Infections}

Eukaryotic cells generate a heterogeneous group of EV subtypes, recognized by biogenesis mechanism and their size (Sedgwick and D'Souza-Schorey, 2018; Théry et al., 2018). EVs have been observed in all body fluids of humans (Raposo et al., 1996; Lässer et al., 2011; Street et al., 2012; Roberts and Kurre, 2013; Hiemstra et al., 2014) and are generated by various cell types (Raposo et al., 1996; Barry et al., 1998; Van Niel et al., 2001; Lai and Breakefield, 2012; Peinado et al., 2012). EVs are responsible for developing the functional range of the bioactive molecules secreted by cells, improving their stability, and boosting their ability to achieve better localized concentrations (Liu et al., 2019; Guo et al., 2021). EVs have an important role in delivery and orchestration of antimicrobial responses from host immune system. In infectious diseases, the cells such as epithelial cells and macrophages have the first contact with the EVs of pathogens that containing bioactive molecules and induce host pro-inflammatory responses (Hui Winnie et al., 2018; Li et al., 2018; White et al., 2021). The stimulated immune cells during infections may produce EVs that convey antimicrobial agents (Kesimer et al., 2009; Hu et al., 2013; Timár et al., 2013) or play decoy roles to protect host cells by binding and coating toxins secreted from bacterial pathogens (da Cruz et al., 2020) (Table 1). Production of EVs by a variety of host cells may be enhanced during infectious diseases (da Cruz et al., 2020).Different types of microorganisms and viruses have all been reported to directly stimulate host EVs secretion (Kim et al., 2012; Antwi-Baffour et al., 2020; Mehanny et al., 2020). The enhancement of host EVs secretion has been shown following an extracellular challenge of alveolar epithelial cells with heatsacrificed bacteria, providing that the activator of this response was bacterial CpG DNA that bond to endosomal receptors of TLR9 (Keller et al., 2020). Host endothelial cells and macrophages infected by bacterial agents are similarly promoted to release EVs (Bhatnagar et al., 2007; Hui Winnie et al., 2018; Li et al., 2018). Besides increasing the production of EVs, infections can alter the contents of EVs produced by host cells (Bhatnagar et al., 2007). MSCs-derived EVs promote healing process in diabetic foot by loading some bioactive molecules including growth factors, nucleic acids, and proteins. Also, as a vehicle for non-bioactive substances like antibiotics can inhibit the bacterial growth and accelerate improvement in the diabetic wound repair in bacteriaassociated diabetic foot ulcers (Raghav et al., 2021).

\section{Bacterial Extracellular Vesicles}

It is now well recognized that most bacteria produce soluble products such as metabolites, quorum sensing peptides, nucleic acids, proteins, and bacterial EVs (BEVs) that allow their communication with each other and host cells (Hughes and Sperandio, 2008; Tulkens et al., 2020). Interestingly, both beneficial and pathogenic bacteria release BEVs. BEVs carry various molecules such as proteins, peptidoglycan, enzymes, toxins, polysaccharides and DNA/RNA molecules (Riley et al., 2013; Kaparakis-Liaskos and Ferrero, 2015). Different BEVs have various structures and even various molecular cargo compounds. These differences may be due to various growth conditions, several biogenesis pathways, the unique membrane envelope structure of the parental bacterium which they emanate from, and also the genetic content of the paternal bacterial strain (Toyofuku et al., 2019). BEVs display high stability to different temperatures and treatments, and regarded safe because they are not able to replicate in vitro and in vivo conditions. They carry several immunogenic surface and membrane related components of their parental strains (Kaparakis-Liaskos and Ferrero, 2015). Based on the originating strains, BEVs can promote both humoral and cellular immunity and together with their nanoparticulate character, provide them with their own adjuvanticity, BEVs are capable to increase T-cell reactions to antigens (Chronopoulos and Kalluri, 2020).

\section{Application of outer membrane vesicles and vaccine development}

Gram-negative bacteria pursue two important routes for BEVs production. The primary pathway is blebbing of the outer membrane of the bacterial envelope, producing OMVs; and the other pathway requires explosive cell lysis forming outer-inner membrane vesicles (OIMVs) and explosive outer membrane vesicles (EOMVs) (Figure 1; Toyofuku et al., 2019; Tulkens et al., 2020). The blebbing process of the membrane giving rise to OMVs happens through a disruption of crosslinks between the outer membrane and the underlying peptidoglycan cell wall layer (Chronopoulos and Kalluri, 2020). Actually, the Gram-negative bacterial cell wall comprises a thin layer of peptidoglycan in the periplasmic environment between two membrane bilayers; the cytoplasmic and outer membranes (Toyofuku et al., 2019; Chronopoulos and Kalluri, 2020). The outer membrane includes lipopolysaccharides (LPS) or endotoxin on its outer leaflet and various membrane-bound channels and protein-like porins that simplify non-vesicle mediated transport. Reflecting this envelope structure, Gram-negative BEVs consist of an outer membrane with an interior leaflet of phospholipids and an exterior leaflet of LPS that is known to engage TLR4 (Toyofuku et al., 2019; Tulkens et al., 2020). BEVs of Gram-negative bacteria contain high concentration of different outer membrane proteins, such as ompA and encapsulated periplasmic luminal compounds. Nevertheless, the existence of cytoplasmic cargo 
including virulence molecules and nucleic acids is debated and dependent on the certain biogenesis pathways of the OMV, OIMVs, and EOMVs (Toyofuku et al., 2019; Tulkens et al., 2020). The endotoxicity of BEVs can be simply modified through genetic engineering methods. Furthermore, BEVs from specific commensal, or beneficial and potentially probiotic bacterial species may excrete therapeutic effects. In future, BEVs may be applied in cancer immunotherapy to elicit durable antitumor immune response or act as anticancer vaccines. In a recent study, the applicability of BEVs in cancer immunotherapy or cancer vaccines was reported showing that systemic intravenous administration of Gramnegative BEVs from the genetically modified Escherichia coli $\mathrm{msbB}^{-1-}$ has a directed tropism for tumor site and a notably capability of inducing long-term antitumor immune responses through the secretion of CXCL10 and INF $\gamma$ that can completely eradicate tumors without considerable adverse consequences (Kim et al., 2017).

\section{Application of membrane vesicles}

Gram-positive bacteria also release nano-sized cytoplasmic membrane vesicles (CMVs), or so-called as MVs, through endolysin-triggered bubbling cell death into the extracellular environment either in a constitutive manner or in a regulated manner (Brown et al., 2015; Toyofuku et al., 2019). Grampositive bacteria lack the entire outer membrane and possess a much thicker peptidoglycan layer or cell wall. The Grampositive cell wall is connected to glycan polymers that can be covalently linked to peptidoglycan [as wall teichoic acids (WTAs)], or anchored in the cell membrane in the case of glycolipids such as lipoteichoic acids (LTAs) which can interact with TLR2 (Brown et al., 2015; Toyofuku et al., 2019; Tulkens et al., 2020). Similar antitumor effects were also seen for the Gram-positive BEVs originated from Staphylococcus aureus and Lactobacillus acidophilus (Chronopoulos and Kalluri, 2020). There is also an enormous interest in applying genetic engineering methods to manipulate bacteria and subsequently purify recombinant BEVs for utility as vaccines against some cancers (Chronopoulos and Kalluri, 2020).

\section{Role of extracellular vesicles in antibiotic resistance and biofilm formation}

The localization of chromosomal DNA in BEVs from different Gram-negative pathogenic bacteria such as Salmonella typhimurium is often extraluminal with smaller amounts settled in the intraluminal locations (Bitto et al., 2017). Sequencing of the intraluminal BEV DNA has been reported to be enriched in certain regions of the bacterial chromosome involved in pathogenicity and virulence capacity, stress response and antibiotic resistance as well as metabolic pathways. There is still a matter of controversy whether extraluminal or surfacesassociated BEV DNAs versus intraluminal ones render different types of actions. One can assume a probable role for external DNA in biofilm formation versus a role for internal BEV DNA in intercellular crosstalk and horizontal gene transfer (HGT) of virulence-associated markers and antibiotic resistance encoding genes (Bitto et al., 2017).

\section{Bacterial extracellular vesicles contribute to immune response}

Bacterial extracellular vesicles contain several microbe-associated molecular patterns (MAMPs) or pathogen-associated molecular patterns (PAMPs) such as peptidoglycan, lipoproteins, LPS and bacterial DNA/RNA. The MAMP content of BEVs enables them to interact with host pattern recognition receptors (PRR) in different types of host cells to induce immune tolerance, or confer protective immunity, and even host cell damage (Riley et al., 2013). The immunomodulatory effects of BEVs mainly depend on the particular parental bacterium and its association with the host. For example, BEVs from some pathogenic bacteria are capable of worsening the infection by suppressing host immune responses (Peek and Blaser, 2002; Lee Hannah et al., 2007), or induce overwhelming immune responses leading to sepsis (Shah et al., 2012). In opposite, BEVs from beneficial or commensal bacteria in the gut can promote immunological maturation and tolerance to confer protection from sepsis (Shen et al., 2012; Kang et al., 2013). In addition, a number of cell surface TLRs, prominently TLR2 and TLR4, can recognize extraluminal ligands of BEV such as LPS, lipoarabinomannan, peptidoglycan and LTA macromolecules (Prados-Rosales et al., 2011; Zhao et al., 2013; Athman et al., 2015; Gu et al., 2019). Also, both nucleotidebinding oligomerization domain-containing protein 1 (NOD1) and NOD2 are engaged in sensing peptidoglycans that are available in BEV contents produced by pathogenic and symbiotic bacterial strains (Kaparakis et al., 2010; Thay et al., 2014; Bitto et al., 2018; Cañas et al., 2018). In addition, intraluminal BEV DNA/RNA may be recognized via DNA/RNA sensing receptors. After endocytosis, BEV RNA cargo may be recognized via endosomal TLRs such as TLR3 and TLR7. In a similar fashion, RNAs rendered into the cytoplasm after fusion of BEVs with the cell plasma membrane may activate cytosolic RNA detectors like RIG-I-like receptors (Tsatsaronis et al., 2018). Similarly, BEV DNA cargo may be sensed by endosomal TLR9 or cytosolic DNA sensing cyclic GMP-AMP synthase stimulator of the interferon genes cascade. Overall, PRR stimulation promotes the activation of transcription factors and kinases that result in the secretion of chemokines and other cytokines leading to the immune cells recruitment and regulation of costimulatory factors normally associated with acquired immune response (Riley et al., 2013).

\section{Extracellular vesicles as infection biomarkers}

As mentioned above, EVs are found in various body fluids like blood, urine and saliva. EVs contain different biomolecules, which can be used as novel biomarkers for a variety of human diseases and cancers. Since they can be obtained by minimally invasive biopsy procedures, thus they would be very useful biomarkers for diagnosis (Lee et al., 2018; Min et al., 2019). As researchers begin to figure out the distribution pattern and composition of EVs during infectious diseases, new biomarkers can be introduced that can provide the possibility for the development of EV-based diagnostics (Tulkens et al., 2020). For instance, serum EVs can used to show biofilm-associated infections to support a rapid detection (Deng et al., 2020). Further understanding of the biology of EVs can provide possible clues to protect infectious diseases and early detection. 


\section{Viral Extracellular Vesicles}

Viral EVs are generated by virus-infected cells and are considered to be engaged in inter/intracellular connection between infected and uninfected cells. Viral agents, especially oncogenic viruses and viruses that can develop chronic infections can regulate the EVs generation and the content. Viruses are defined by the virologists of last century as "submicroscopic infectious agents that can replicate only inside the living cells of an organism". EVs do not fall under this description, because contrary to their similarity to viruses in many aspects, they are basically distinct, as they are non-replicative particles. Nevertheless, current virology has distanced itself from such an out-dated description of virus by new terms of defective and non-infectious particles. Thus, EVs produced by virus-infected cells that contain different viral proteins and some parts of viral genomes can fall under the description of non-infectious viral agents (Nolte-'t Hoen et al., 2016). Moreover, there is a resemblance between biogenesis of virions and EVs. EVs and virus particles are altogether released by infected cells and share the routes for biogenesis at the plasma membrane (Colombo et al., 2014). Regardless of what described, it is essentially difficult to discriminate between EVs that deliver viral proteins, viral genomic fragments and host proteins and enveloped viral particles that carry the similar contents (Nolte-'t Hoen et al., 2016).

\section{Effects of extracellular vesicles on viral pathogenesis}

It was shown that cells infected with enveloped or nonenveloped viruses produce EVs that carry viral constituents. The preparation of viral particles may not be completely pure and are almost mixed with various types of EVs, and even some of these EVs may be either indiscernible from defective viruses. Due to their close biogenesis routes, EVs and viral particles may be near relatives, however only viruses can replicate inside the cells. Notably, EVs produced via infected cells are not neutral, as they may facilitate virus spread and viral infection or increase antiviral responses (Nolte-'t Hoen et al., 2016). For instance; numerous HIV RNAs and proteins have been identified in EVs produced from HIV-infected cells (Narayanan et al., 2013). The involvement of EVs in viral infection has already been described for many viruses, including rabies, coronaviruses, HCV, HIV, HPV, HSV, dengue, HTLV-1, Zika, West Nile Epstein Baar virus, influenza virus, and SFTS (Martins and Alves, 2020). Deciphering the EVs structure produced by infected cells, characterizing their cargo, and understanding the accurate strategy by which they affect viral infection are necessary for basic virology and therapeutic applications as well (Nolte-'t Hoen et al., 2016).

\section{Effects of viral extracellular vesicles on host immunity}

The process of infection may alter the contents of cells-derived EVs and change the ratios of host RNAs and proteins inside them (Nolte-'t Hoen et al., 2016). Upon infection process, EVs can intensify inflammatory responses and deflagrate antiviral activities (Urbanelli et al., 2019), also can mediate the crosstalk between immune cells and other cells (Isola and Chen, 2017; Rezaie et al., 2021). Those EVs which can be transferred between the immune cells may transmit signals affecting the chemokines or cytokine secretion level, and some EVs can directly activate antigen presentation (Lindenbergh and Stoorvogel, 2018). Also, EVs carry different cytokines and cytokine-associated RNAs that may trigger the generation of target molecules in recipient cells, contributing to antiviral responses (Urbanelli et al., 2019). Moreover, EVs produced by infected cells were able to trigger other cell types, as observed when EVs produced by U937 macrophages, contaminated with DENV-2, activated endothelial cells (Velandia-Romero et al., 2020). Also, EVs secreted from airway epithelial cells infected by respiratory syncytial virus (RSV) can enhance the expression of regulatory small RNAs and may activate chemokine and cytokine secretion in monocytes without being exposed to infective particles (Chahar et al., 2018).

Further, EVs are capable to mediate the severity of disease though increasing the secretion of pro-inflammatory cytokines associated with several infectious diseases. EVs derived from bronchoalveolar fluid of mice infected with $\mathrm{H} 5 \mathrm{~N} 1$ influenza virus displayed enrichment with miR-483-3p, which stimulates innate immunity in pneumocytes proposing the involvement of EVs in the inflammatory pathogenesis of H5N1 virus (Maemura et al., 2020). In addition, in dengue hemorrhagic fever, EVs were observed to play an important role in the disease development (Mishra et al., 2019).

\section{Immune cell-derived extracellular vesicles and antiviral effects}

Extracellular vesicles can interact with each other and with viruses in vivo either directly or indirectly though modulating the host responses, therefore they are engaged in a "War and Peace" scenario between host and viruses (Lisco et al., 2009; Bhattarai et al., 2015). In opposite, EVs containing viral proteins can be profitable to the host cells. For instance, they can present viral antigens to DCs to facilitate triggering activation of adaptive immunity. Therefore, EVs produced within viral infection may demonstrate either proviral or antiviral features. It has been shown that $\mathrm{T}$ cells could release EVs comprising HIV receptor CD4. Such EVs can directly bind to viral particles, thereby reducing the load of virions that would otherwise infect other $\mathrm{CD}^{+} \mathrm{T}$ cells (de Carvalho et al., 2014). Thus, further investigations are required to uncover the exact roles of EVs in antiviral immune responses in order to direct EVs engineering that may exhibit robust antiviral potentials.

\section{Host Extracellular Vesicles as Antimicrobial Responses}

Host EVs produced by immune cells have been demonstrated to elicit strong antimicrobial effects in in vitro and in vivo conditions (Timár et al., 2013; Wang C. et al., 2019). These antimicrobial potencies are contributed to various bacteriostatic and bactericidal compounds present in the EVs cargo (Table 1) (Timár et al., 2013; Hiemstra et al., 2014). For instance, EVs obtained from human urinary tract are usually enriched in proteins with immune functions, such as bacteriostatic proteins like mucin-1, fibronectin, CD14, and also bactericidal proteins such as calprotectin, dermcidin and lysozyme C (Hiemstra et al., 2014). Moreover, such EVs hindered the growth of probiotic and uropathogenic strains of E. coli as well as its laboratoryadopted strains, and mediated the bactericidal functions through 
a lytic process (Hiemstra et al., 2014). Also, EVs are assumed to stabilize bioactive components like RNAs, and affect the non-lethal pathways of controlling microbial behaviors (Liu et al., 2016). EVs released from the host cells upon exposure to pathogenic microbes may also be able to safeguard cells from microbial assaults via efficient imitating the targets of their toxins and functioning as decoys (Keller et al., 2020).

\section{Immunomodulatory Functions of Extracellular Vesicles Derived From Mesenchymal Stem Cells}

Mesenchymal stem cells (MSCs) are multipotent stem cells derived from mesoderm and have the ability to differentiate into a variety of cells. They can be easily obtained from many sources including mature tissues such as bone marrow (BM), peripheral blood (PB), adipose tissues (AT) and neonatal birthrelated tissues including amniotic fluid (AF), Warton jelly (WJ), umbilical cord (UC), placenta (PL), and cord blood (CB) (Seo et al., 2019). These heterogeneous cells possess significant immunomodulatory and protective characteristics (Dabrowska et al., 2021). They are also modulate immune cell responses and produce various inflammatory mediators by which they can regulate both innate and adaptive immune responses. When the responses of some immune cells such as macrophages, natural killer (NK) cells, DCs, B and T cells are exaggerated, MSCs can repress their proliferation, differentiation, and activation to modulate the immune response (Ren et al., 2008). These immunomodulatory effects are exerted through the production of several soluble mediators such as nitric oxide (NO), indoleamine 2, 3-dioxygenase-1 (IDO-1), transforming growth factor- $\beta 1$ (TGF- $\beta 1$ ), interleukin-10 (IL$10)$, prostaglandin-E2 (PGE2), and hepatocyte growth factor (HGF) to the microenvironment (Puissant et al., 2005). Such immunomodulatory effects of MSCs might be associated with EVs which they release to the environment. It has been shown that EVs released from MSCs can inhibit the proliferation and differentiation of B lymphocytes in a dose-dependent manner (Budoni et al., 2013). Also, EVs produced by murine BM-MSCs inhibit the proliferation of $\mathrm{T}$ lymphocytes and modulate the adaptive immune system in mice via inducing of apoptosis in the activated T lymphocytes. This increases the number of regulatory $\mathrm{T}$ cells, and enhancing the secretion of anti-inflammatory cytokines such as IL-10 and TGF- $\beta 1$ (Mokarizadeh et al., 2012). Notably, it has been reported that galectin-1 and programmed death receptor ligand (PD-L1) were present on the surface of EVs derived from MSCs (Garín et al., 2007). Endogenous galectin-1 induces apoptosis in the activated $\mathrm{T}$ lymphocytes and provoke the maturation of regulatory $\mathrm{T}$ lymphocytes (Rabinovich et al., 2000). PD-L1, on the other hand, is a ligand of the PD-1 receptor and induces the proliferation of regulatory $\mathrm{T}$ cells proliferation. TGF- $\beta$ is another component of MSC-EVs, which also activates the formation of regulatory T cells (Chen et al., 2003).

The MSC-EVs have been shown to exhibit immunomodulatory properties in vivo. For example, it was shown that EV-treated mice demonstrated lower white blood cells (WBCs) counts and decreased neutrophil and monocyte influx into the hearts after myocardial ischemia reperfusion (MI/R) injury as compared to controls (Arslan et al., 2013). Also,
MSC-EVs were able to switch the macrophages from a proinflammatory (M1 macrophages) to an anti-inflammatory (M2 macrophages) in the cardiomyopathy mice model and reduced the secretion of pro-inflammatory cytokines such as IL-1, IL-6, and TNF- $\alpha$ (Sun et al., 2018). The immunosuppressive effects of MSC-EVs on the liver injury animal models were also reported. It has been shown that the expression of pro-inflammatory cytokines such as IL- 1 , IL-2, TNF- $\alpha$, IFN- $\gamma$ was reduced while anti-inflammatory cytokines including TGF- $\beta$ and HGF, and the number of $\mathrm{T}$ regulatory cells increased in the liver tissue following treatment with MSC-EVs (Tamura et al., 2016).

\section{Mesenchymal Stem Cell Therapy for COVID-19 and the Other Viral Infections}

Coronavirus disease 2019 (COVID-19) is a life-threatening infectious disease caused by a newly emerged coronavirus named severe acute respiratory syndrome coronavirus 2 (SARS-CoV2). Patients infected with this virus will experience mild to severe respiratory disease (Rezasoltani et al., 2020a). There are currently no specific antiviral treatments licensed for COVID-19, however many treatments are under investigation (Rezasoltani et al., 2020b; Shpichka et al., 2021). Hopefully, the management of severe acute respiratory infection form of COVID-19 significantly can decline the death rate, particularly within the high-risk people. Several preclinical and clinical studies have exhibited the effects of exosomes and MSC-EVs in decreasing cytokine storm-associated complications, such as alveolar inflammation, edema, and epithelial tissue regeneration in inflammatory diseases, such as chronic obstructive pulmonary disease (COPD), asthma, acute respiratory distress syndrome (ARDS), and acute lung injury (ALI) (Akbari and Rezaie, 2020; Keller et al., 2020). Recently, MSCs-based immunomodulation therapy has been suggested as an effective treatment option for COVID-19 and multiple clinical trials have been launched so far (Akbari and Rezaie, 2020; Golchin et al., 2020). Since it has been suggested that the therapeutic effects of MSCs are essentially due to their secreted EVs, clinical trials may begin to apply MSCderived exosomes and their EVs to alleviate the cytokine storm in severe COVID-19 patients (Akbari and Rezaie, 2020). However, there are some concerns over the safety, efficacy, and scalability of clinical-grade MSC-EVs (Golchin et al., 2020).

\section{Secretion of Antimicrobial Peptides and Proteins}

Associated molecular patterns are a miscellaneous class of naturally occurring small effector molecules that play a key role as the first line of defense by all multicellular organisms. AMPs can have wide killing activity against different types of microorganisms and even cancer cells. These biomolecules can also be referred to as 'host defense peptides', highlighting their additional immunomodulatory functions. Such functions are diverse, unique to AMP type, and involve a number of growth factor-like and cytokine effects that are contributed to normal immune homeostasis status (Seyfi et al., 2020). Some studies showed that MSCs elicit potent antimicrobial activities via indirect and direct mechanisms, partially mediated by the production of antimicrobial peptides and proteins (AMPs) of members of the cathelicidins, defensins, hepcidin, or lipocalin 
families as discussed below (Krasnodembskaya et al., 2010; Sung et al., 2016; Alcayaga-Miranda et al., 2017).

\section{Cathelicidin LL-37}

Cathelicidin LL-37 is the C-terminal part of the host cathelicidin, called human cationic antimicrobial protein (hCAP18), which is mostly produced by epithelial cells and neutrophils. The cathelicidin hCAP18/LL-37 is a multifunctional molecule that may regulate different human cellular and molecular processes such as epithelial cell activation, chemotaxis, bactericidal function, angiogenesis, and activation of cytokine and chemokine production. This antimicrobial peptide is produced from host cells upon infection of mycobacteria and exerts a bactericidal activity (Sandra Tjabringa et al., 2005). Besides a broad range of antimicrobial activity, LL-37 shows multiple immunomodulatory effects, anticancer functions, and also pro-angiogenic and chemotactic features. LL-37 has been found in many types of body fluids, tissues, and cells, and along with AMPs plays a critical role in host mucosal defense against microbial infections (Alcayaga-Miranda et al., 2017).

\section{Human $\beta$-defensin-2}

The hBD-2 is a cysteine-rich, cationic, low molecular weight antimicrobial peptide that is predominantly microbicidal against Gram-negative bacteria. It is expressed by many epithelial cells, granulocytes, and MSCs (Alcayaga-Miranda et al., 2017). The $\mathrm{hBD}-2$ is a remarkable, inducible, antimicrobial peptide in a variety of epithelial cell types including skin cells, airways, kidney, oral mucosa, and gastrointestinal tract (Harder et al., 2000; Kumar et al., 2006). Its production is also induced by proinflammatory stimuli such as TNF $\alpha$ or microorganisms. The hBD-2 serves as a dynamic part of the local epithelial defense system of respiratory tract and skin which protect surfaces from infection. This is the reason why lung and skin infections caused by Gram-negative pathogens are rather rare (Li et al., 2016). Thus, based on significant antimicrobial and antiviral functions, modulating endogenous production of defensin by certain regulatory factors makes them promising therapeutic options against microbial infections.

\section{Hepcidin}

Hepcidin is a peptide encoded by the HAMP gene in human and is a natural host defense peptide found in urine (Nikfarjam et al., 2020) and plasma (Babaei and Rezaie, 2021). This peptide produces mainly by hepatocytes but other cells such as MSCs and myeloid leukocytes are also produce and release these peptides (Balhuizen et al., 2021). Two forms of hepcidin peptide, hep-20 and hep-25, exhibit antimicrobial properties (Nikfarjam et al., 2020) but hep-25 (LEAP-1) is also involved in the iron regulation (Chronopoulos and Kalluri, 2020). Beyond the iron regulatory effects, hepcidin has a broad spectrum of antibacterial and antifungal activity. For example, the antibacterial activity of this peptide against Escherichia coli, S. epidermidis, S. aureus, and group $B$ streptococci has been shown previously which demonstrates its role as an antimicrobial peptide (Bitto et al., 2017). Incorporation of hepcidin into the EVs derived from the hepatocytes, MSCs, and myeloid leukocytes can be a mechanism for the prevention of microbial diseases.

\section{Lipocalin-2}

Lipocalin-2, also known as neutrophil gelatinase-associated lipocalin (NGAL), siderocalin, or $24 \mathrm{p} 3$, is a protein mainly secreted by neutrophils in response to infection and inflammation (Deng et al., 2020). Lnc2 blocks the siderophore iron-acquiring strategy of bacteria which leads to bacterial growth inhibition. It was shown that $\mathrm{Lcn} 2$-deficient $\left(\mathrm{Lcn} 2^{-/-}\right)$ mice were more sensitive than wild-type mice to bacterial infection (Nolte-'t Hoen et al., 2016; Urbanelli et al., 2019). Moreover, Lcn2 is one of the components of the innate immune response against bacterial infection (Deng et al., 2020). MSCs are able to produce the Lnc2 protein and upregulation of this protein is directly corrected with bacterial clearance. Administration of antibodies against the Lnc2 protein have been found to block antimicrobial effects of MSCs (Riley et al., 2013).

\section{Indoleamine 2, 3-dioxygenase}

Mesenchymal stem cells secrete several soluble factors, including indoleamine 2, 3-dioxygenase (IDO). IDO is a tryptophandegrading enzyme with antibacterial properties. IDO is involved in the antibacterial defense of some human cells and this was shown by using IDO specific inhibitors or by antagonizing the antibacterial effect with supplemental tryptophan. This enzyme acts against both intracellular (especially Chlamydia species) (Golchin et al., 2020; Dabrowska et al., 2021) and extracellular bacteria such as Staphylococcus aureus, Streptococcus suis, enterococci, and group B streptococci (Sandra Tjabringa et al., 2005; Alcayaga-Miranda et al., 2017). EVs derived from MSCs and containing IDO might be able to fight microbial diseases and reduce their growth rate in vitro.

\section{Interleukin-17}

Interleukin-17 (IL-17), a pro-inflammatory cytokine, contributes to host defense against both extracellular and intracellular pathogens. The antibacterial properties of this cytokine against Aspergillus fumigatus, Cryptococcus neoformans, and Candida albicans were demonstrated (Lombardi et al., 2015; Wang Q. et al., 2019). A variety of cells including $\mathrm{CD} 4^{+} \mathrm{Th} 17$ cells, $\mathrm{CD} 8^{+}$ $\mathrm{T}$ cells (Tc17), natural killer T (NKT) cells, macrophages, and IL$17^{+}$MSCs have the capacity to produce IL-7 (Yang et al., 2013; Mardpour et al., 2018; Duong et al., 2019; Shpichka et al., 2021). The IL- $17^{+}$MSCs are able to inhibit the growth of C. albicans in vitro and have a therapeutic effects on C. albicans-infected mice (Schroten et al., 2001). EVs derived from these MSCs, can inhibit bacterial growth.

\section{Potential Application of Stem Cell-Derived Extracellular Vesicles on Pathogenic Microbes Extracellular Vesicles as a Unique Drug Delivery System}

Targeted drug delivery is among the most significant challenge in pharmacology and pharmaceutical sciences (Nolte-'t Hoen et al., 2016). Distinctive properties of EVs favor their utilization as novel DDSs over synthetic ones (Figure 2). These characteristics include their capability to cross physical barriers, their biocompatibility, their inherent targeting features, and also 
their ability to exploit natural intracellular trafficking pathways (Elsharkasy et al., 2020). Interestingly, viruses incorporate specific binding proteins, and thus are highly targeted mostly due to their evolved and acquired high specificity toward their cellular targets. The EVs membrane can be engineered to incorporate with such specific viral proteins to facilitate EVmediated transfer of drugs (György et al., 2015). Also, genetically manipulated cells from which EVs are originated, have been developed to provide distinct platforms for loading cargo and conjugation of targeting moieties to their EVs. However, further in-depth investigations into EV biogenesis, EV subpopulations, cargo sorting, internalization and trafficking routes in recipient cells are required to achieve translational applications of such engineered EVs. Furthermore, there are a number of obstacles that should be addressed toward clinical use and include scale-up of the EV production and isolation process, as well as standard protocols for proper banking (Elsharkasy et al., 2020).

\section{Decoy Exosomes}

Decoy exosomes represent a new class of therapeutic biologics that are generated by molecular engineering approaches to treat human diseases including inflammation, cancer, and cardiovascular disorders (Zhang et al., 2021). This type of exosomes functions as a biological sponge to absorb and antagonize detrimental factors such as bacterial toxins and inflammatory mediators particularly, $\mathrm{TNF} \alpha$, in host blood or tissues (Figure 2; Duong et al., 2019). Nonetheless, the scale-up production of decoy exosomes from more suitable producing cells is essential to obtain high-quality exosomes for therapeutic utilization against infections and inflammatory diseases.

\section{Extracellular Vesicles as Vaccine Platform}

Extracellular vesicles from pathogenic bacteria usually carry PAMPs and MAMPs which authorize them to activate the immune response, macking them the ability to be applied as vaccine candidates (Figure 2; Sharpe Samantha et al., 2011; Gorringe and Pajón, 2012; Bartolini et al., 2013; Mehanny et al., 2020). For instance, the BEVs from Neisseria meningitides, have been applied as the basis for a vaccine against meningococcal disease, as they induce antibacterial immune responses (Gorringe and Pajón, 2012). The outstanding outcomes of BEVs-based vaccines demonstrated a new avenue and proposed novel strategies to immunize individuals against pathogenic bacteria (Gorringe and Pajón, 2012; Fantappiè et al., 2014; Shkair et al., 2021). Moreover, EVs derived after viral inoculation may further be applied to develop more effective vaccines against viral infections by adding or expelling certain subpopulations of them. In contrast to utilizing pathogenic BEVs for vaccine targets, it has been proposed that BEVs originated from symbiotic bacteria may exhibit modulatory effects on host immune system. For instance, Bacteroides fragilis can selectively deliver capsular polysaccharide

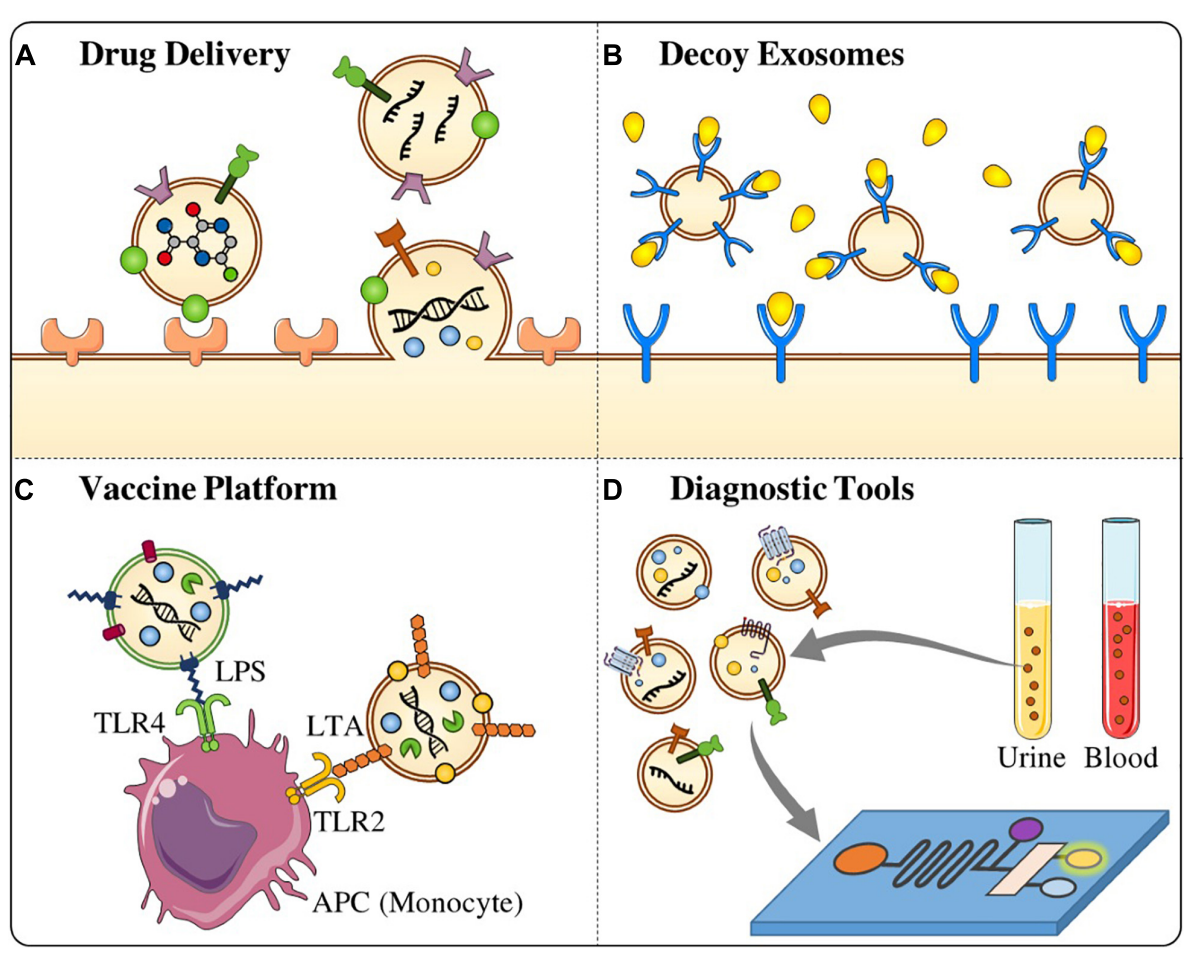

FIGURE 2 | Potential application of stem cell-derived EVs on pathogenic microbes. (A) Stem cell-derived EVs can be used as a targeted drug delivery tool against infectious microbes. (B) Decoy exosomes are a biological trap which can absorb and antagonize detrimental factors such as bacterial toxins and inflammatory mediators. (C) EVs derived from MSCs are also can be used as vaccine platform to activate the immune response and react against the infectious diseases. (D) MSCs-derived EVs are good candidate for the development of diagnostic tools as they are involved in several biological processes and isolated from different biofluids. 
A (PSA) cargo in its BEVs that have been shown to induce immunomodulatory responses and prevent colitis in mice. These data support the rationale for designation of novel probiotic formulations based on specific beneficial BEVs which can be used for therapeutic purposes (Muraca et al., 2015; Choi et al., 2017).

\section{Cell-Derived Extracellular Vesicles as Diagnostic Tools}

Extracellular vesicles are involved in several biological processes and isolated from different biofluids which make them valuable biomarkers for the early diagnosis or prognosis of various diseases such as cancer, inflammatory diseases, and infections (Figure 2; Wei et al., 2021). Thus, these vesicles can be regarded as interesting and non-invasive biomarkers for the diagnosis of different diseases (Wei et al., 2021). EVs isolated from the blood have gained significant interest mainly in the context of tumor diagnosis, and their fluctuations are associated with tumor progression, metastasis, and immune evasion (Palmirotta et al., 2018; Nikfarjam et al., 2020; Salimi et al., 2020). Glypican-1 (GPC1), for instance, as a cell surface proteoglycan, is specifically expressed by exosomes isolated from the serum of pancreatic cancer patients, and it is used as an early biomarker. Further, it has been reported that levels of $\mathrm{GPC}^{+}$exosomes are correlated with pancreas tumor burden and survival rate (Melo et al., 2015). EVs also can be used for the detection of early stages of metastasis. For example, in the exosomes of patients with metastatic melanoma, MDA-9 and GRP78 proteins have higher expression than those of patients without metastases (Guan et al., 2015). Moreover, EVs as urinary biomarkers have been introduced for the early diagnosis of a variety of kidney and genitourinary tract disorders (Street et al., 2017). Neutrophil gelatinase-associated lipocalin (NGAL) (Alvarez et al., 2013), polycystin-1 (PC1) (Hogan et al., 2015), transmembrane protein 2 (TMEM2) (Hogan et al., 2015), and WT-1 (Wilms' tumor-1) (Zhou H. et al., 2013) are some exosomal biomarkers that can be applied for the diagnosis of renal diseases. Some exosome/EV products are commercially available for the diagnostic purposes. For example, ExoDX Lung (ALK), the world's first exosomebased diagnostic kit, was developed and passed FDA certification in Wei et al. (2021).

As aforementioned, EVs have been considered as reliable biomarkers in the context of infectious diseases. From a diagnostic point of view, EVs carry antigens from parental cells and act as reporters of foreign agents (Yáñez-Mó et al., 2015). In the $M$. tuberculosis-infected patients, mycobacterial proteins responsible for $M$. tuberculosis intracellular survival were identified from their secreted exosomes (Kruh-Garcia et al., 2014). It was shown that the mRNA (Lv et al., 2017) and miRNA (Lyu et al., 2019) profiles of exosomes derived from the sera of healthy cases and patients with active and latent tuberculosis were different, which could be used as a diagnostic biomarker. Moreover, human macrophages infected with Yersinia pestis and Bacillus anthracis secrete particular miRNA-containing exosomes (Fleming et al., 2014). LPS induces the murine bone marrowderived dendritic cells (BMDC) to secrete exosomes containing miR-146a and miR-155 (Jiang et al., 2019). Helicobacter pylori infection also exhibits an increase in miR-155 level in the exosomes derived from macrophages (Wang et al., 2016). These miRNAs are proper biomarkers for the rapid detection of such infectious diseases.

\section{THE DRIVER CHALLENGES FOR THE APPLICATION OF STEM CELL-DERIVED EXTRACELLULAR VESICLES IN CLINIC}

The process of manufacturing MSC-EVs in the clinic needs donor identification and screening. Donor identification and screening need a complete review of risk factors, relevant communicable disease agents, and diseases as outlined in FDA 21 CFR Donor Screening 1271.75. Common sources of MSCs and then EVs for the clinical application are those derived from bone marrow and adipose tissue. The EVs harvested from these tissues are then further characterized for their identity, purity, potency, and sterility. Currently, several challenges for manufacturing the clinical-grade EVs are ongoing, and many modifications and optimizations are needed to ensure the safety and reproducibility of the EVs as therapeutic agents (Wiest and Zubair, 2020). Some of the challenges are briefly described below (Figure 3).

\section{Identity}

Due to their nanometer to micrometer scale, detection of EVs by means of currently available lab equipment is challenging. Also, the tissue sources of the MSCs have an impact on the EVs characteristics. It was shown that the origin of the MSCs has an impact on the amounts and sizes of EVs. Exosome samples isolated by ultracentrifugation (UC) and tangential flow filtration (TFF) showed abundant expression of CD81 and CD9 markers and depletion of calnexin as compared to parental cells, but CD63 marker was only expressed on UC-isolated EVs (Haraszti et al., 2018). Therefore, different isolation methods produce different populations of EVs, and thus emphasize the need for standardized good manufacturing practices (GMPs). Because of different components of EVs, some databases such as ExoCarta, Vesiclepedia, and EVpedia have been established in recent years (Keerthikumar et al., 2016; Pathan et al., 2019). These databases have valuable resources for the identification of different EVs, but some specific and universal markers for each EV have not yet been provided. Therefore, further studies are required for the precise characterization of EVs and determining their identity.

\section{Purity}

Since EVs are derived from different cells, including MSCs, they may contain some impurities. For example, fetal bovine serum (FBS) is often added to the MSCs culture media. It was shown that FBS fractions contain RNA molecules and deep sequencing of these fractions showed that $13.6 \%$ and $21.7 \%$ of the RNA in cell pellet and supernatant mapped to the human genome, respectively (Wei et al., 2016). Some laboratories employed the UC for the removal of the majority of EVs and miRNAs found in the FBS (Shelke et al., 2014; Wei et al., 2016). Because of xenobiotic contents of FBS, some manufacturers used human 


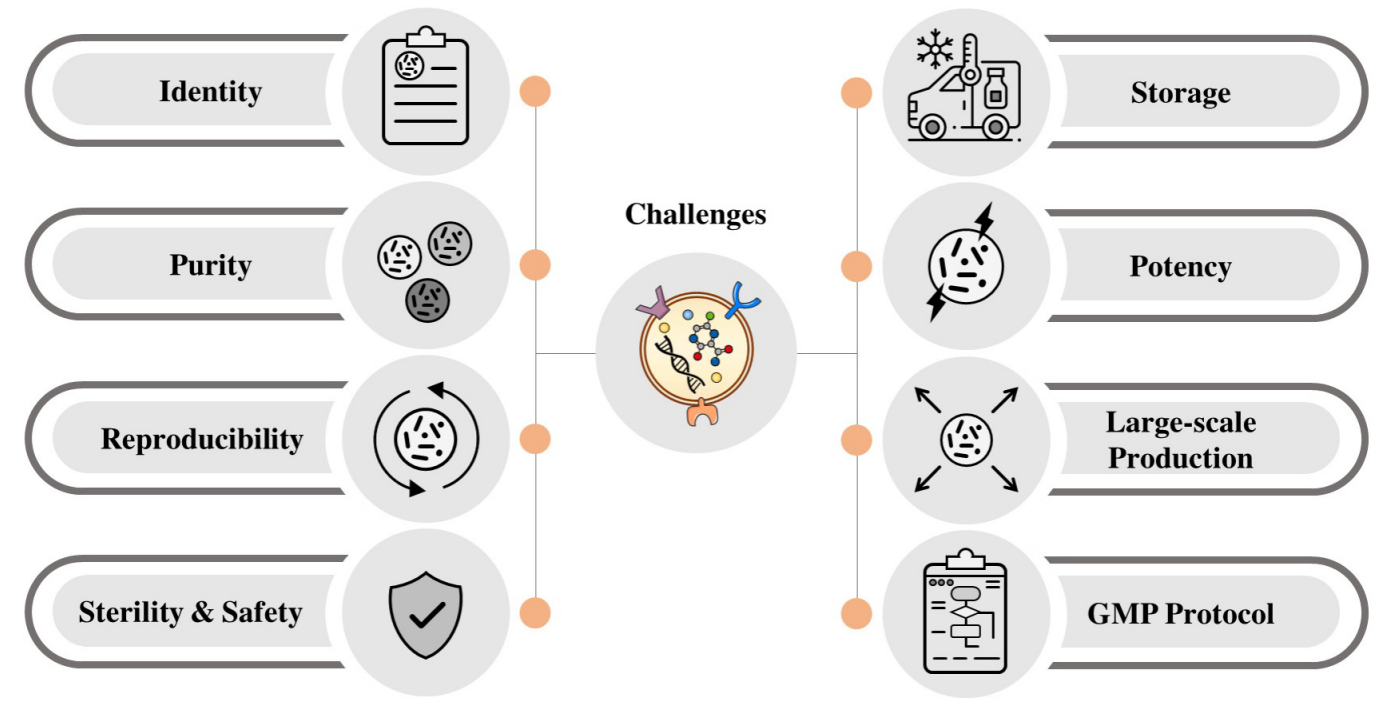

FIGURE 3 | Main challenges for the application of stem cell-derived EVs in clinic.

platelet lysate instead of FBS. Human platelet lysate is xenobioticfree and fibrinogen-depleted and can be used for MSCs culture in GMP studies. It was shown that UC could be able to eliminate the serum-derived RNAs in the lysates (Pachler et al., 2017b). It should be noted that EVs isolated by UC and anion exchange chromatography have similar markers and size distribution, but EVs enriched by TFF are not similar (Heath et al., 2018). Other methods were developed to improve the EVs' purity include quantification of protein to particle ratio (Webber and Clayton, 2013) and protein to lipid ratio (Osteikoetxea et al., 2015); however, these methods still have some limitations.

\section{Reproducibility}

Many factors influence the content and amount of EVs released by cells and there are currently no standard protocols for the isolation and storage of EVs (Lener et al., 2015). Also, there is MSC donor-to-donor and batch-to-batch variation (Russell et al., 2018). It was shown that EV s are highly sensitive to cell stress, and their content may be changed in response to stress. For example, treatment of human placental cells with tunicamycin induces ER stress in these cells and leads to the release of EVs containing HSP70 and HMGB1 (Collett et al., 2018). The content of the cell culture media, the composition of the serum added to the media, and the drug interactions affect the EVs' integrity (Wiest and Zubair, 2020). Isolation methods also change the composition of EVs. Haraszti et al. showed that when MSCs were grown in $3 \mathrm{D}$ culture conditions and isolated by TFF, displayed a different protein content compared to other methods of culturing and isolation (Haraszti et al., 2018). Most studies focus on UC as a gold standard for the isolation of EVs. Busatto et al. (2018) reported that when they used the US for isolation, the size distribution and albumin purity of samples changed significantly from batch-to-batch, but using TFF, in contrast, showed less batch-to-batch differences. These studies highlighted the factors affecting the reproducibility of EVs and emphasized the need for the development and validation of isolation methods.

\section{Sterility and Safety}

Sterility tests are assays performed by manufacturers to determine the microbial contaminations. Strict donor eligibility criteria and screening methods for diseases are the first steps for the determination of sterility and safety of the products. The companies generating EVs must comply with FDA Title 21, Part 610 (Wiest and Zubair, 2020). Microbial contamination is important not only for the safety of the recipients, but also some microbes produce and secret EVs which might interfere with the EVs in the therapeutic product (Quah and O'neill, 2007; Giri et al., 2010). The size of some viral particles is similar to EVs which raises some challenges for EV isolation by sizedependent techniques such as TFF and other chromatographybased methods (Matthews, 1975). TFF is better than UC for reducing the risk of contamination because TFF method can be conducted in a closed system, but UC technique requires multiple steps and requires multiple transfer of the fractions to the new containers (Wiest and Zubair, 2020).

Due to cell-free nature, EVs are hypothesized to be safer than other products, but there are limited data about the safety profile of EV-containing compounds (Wiest and Zubair, 2020). A shortterm safety study was conducted by Montaner-Tarbes et al. (2018), where they treated healthy pigs with EVs derived from pigs with the porcine syndrome. They found that healthy pigs treated with EVs have no signs of the disease (Montaner-Tarbes et al., 2018). Until recently, adverse events (AEs) or toxicity related to EVs-based treatments are rarely reported (Nassar et al., 2016; Saleh et al., 2019).

\section{Storage}

Extracellular vesicles are very sensitive to temperature and $\mathrm{pH}$ of the storage buffer (Wiest and Zubair, 2020). The ideal 
temperature for the long-time storage of EVs is $-80^{\circ} \mathrm{C}$ (Otrokocsi et al., 2014). It has been shown that the quantity of EVs decreases in a time-dependent manner when they are stored at room temperature or $4^{\circ} \mathrm{C}$ following isolation. Also, the results of the light-scattering analysis demonstrated a notable time-dependent increase in the structural changes of EVs when they stored for a long time at $-20^{\circ} \mathrm{C}$ (Otrokocsi et al., 2014). Changes in the $\mathrm{pH}$ of the storage buffer can induce EVs' aggregation and loss of their functionality (Lener et al., 2015). The storage buffer is also an important factor for maintaining the EVs' functionality. The phosphate-buffered saline was exploited in the majority of published studies as the EVs storage buffer ( $\mathrm{Li}$ et al., 2019; Marcoux et al., 2019), but others also have used sucrose buffer (Busatto et al., 2018), lactated Ringer's solution (Pachler et al., 2017b), and PBS supplemented with trehalose (Bosch et al., 2016) for the storage of EVs. The type of EVs and their application may require different storage buffers and maintaining conditions.

\section{Potency}

Despite the difficulties in identifying active components in the EVs, potency determination becomes more popular in the last few years in preclinical studies (Wiest and Zubair, 2020). Due to the pleiotropic effects of proteins and RNAs contained within EVs, identifying the active ingredients in exosome therapy is challenging. EVs' potency assays are promising methods to overcome the challenges of identifying an active ingredient. The basics of many potency assays is the release of pro-inflammatory cytokines by M1-phenotype macrophages. To do this, EVs must be added to the culture of M1-phenotype macrophages and the desired inflammatory marker is measured based on the dose of EVs (Pachler et al., 2017a; Willis et al., 2018). These methods are used frequently for the potency evaluation but further research is needed to validate their applications.

\section{Large-Scale Production}

Large-scale production of EVs for clinical applications needs scale-up culture of MSCs, but long-term passaging may result in losing clonal and differentiation capacity of cells (Raghav et al., 2021). Therefore, it is necessary to develop new methods for reliable expansion of MSCs to mass-produce EVs for clinical use. Also, large-scale culture of MSCs in bioreactor requires the addition of some ingredients such as fibronectin for cell adherence purposes. Fibronectin as an ingredient has some complications because this protein makes clogging in filter pores and interferes with the size-based selection of EVs using the TFF method. Therefore the conditioned media need an extra centrifugation step, which make the risk of contamination more (Wiest and Zubair, 2020).

\section{Developing a Good Manufacturing Practice Protocol}

For the production of EVs in large quantities, the companies demand a standardized manufacturing process which must comply with GMP regulations (Mobarak et al., 2021). The GMPgrade production of EVs is a process that depends on the cell type, culture media, cultivation, and purification methods. In the case of cell type, five cell types including bone marrow and adipose tissue-derived MSCs, monocyte-derived dendritic cells (DCs), human cardiac progenitor cells, and HEK293 cells have been used in GMP-grade for production of EVs. Cultivation methods employ both static and dynamic systems. Flask based systems are static but bioreactor systems are dynamic (Rezaie et al., 2021). In the GMP-grade production of EVs, bioreactor systems are preferred due to the dynamic monitoring system (Akbari and Rezaie, 2020). In the case of purification of GMPgrade products, a number of steps including filtration for the removal of cell debris, centrifugation for enrichment of the conditioned media, and isolation of EVs from the media

TABLE 1 | Current biomedical applications of Extracellular vesicles.

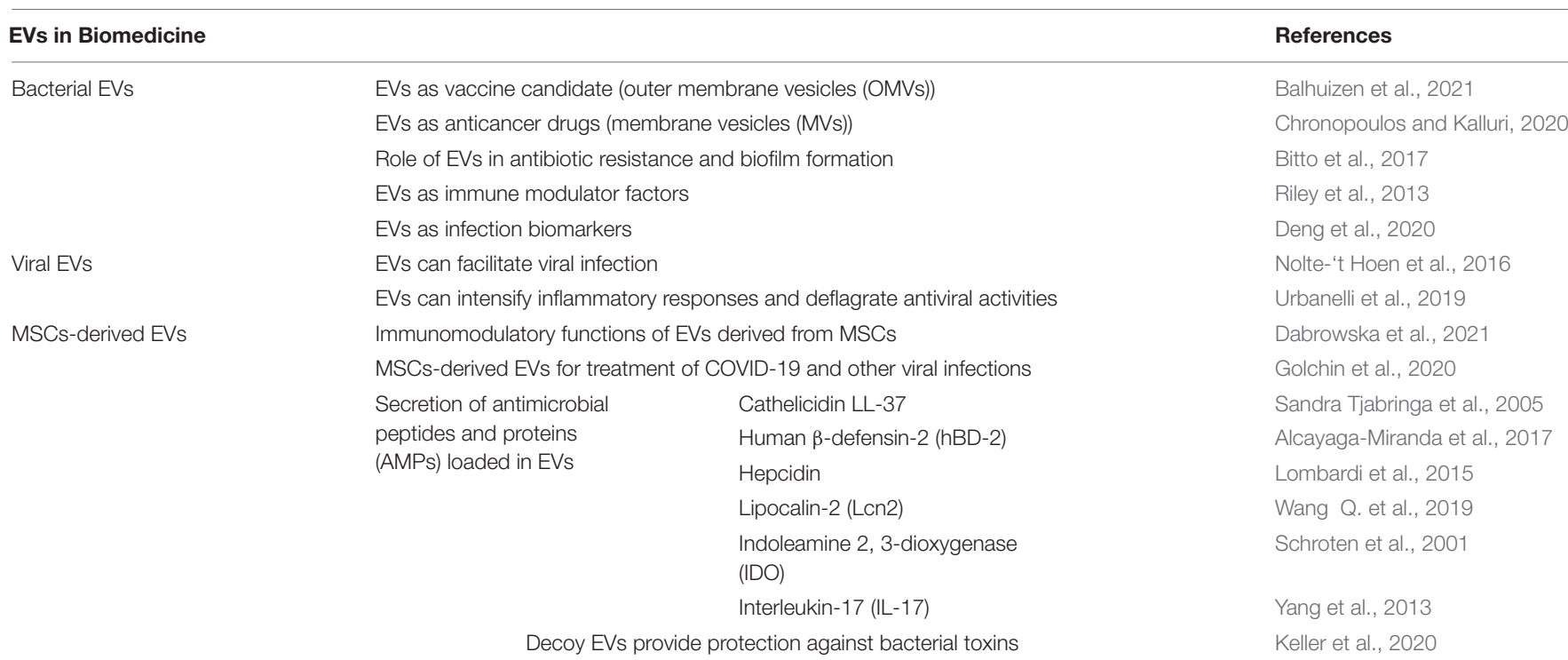


should be performed. Differential centrifugation, despite its complications, is the preferred method for concentrating the conditioned media (Salimi et al., 2020).

\section{CONCLUSION}

In recent years we have witnessed remarkable progress in the biology of EVs and their impact on microbial diseases. Now, a clear picture has emerged and showed that MSCs-derived EVs may play a crucial role in infectious diseases. MSCs-derived EVs retain the biological activity of parental MSCs and have a similar therapeutic potential. Evs derived from MSCs have potent antimicrobial activity by production of antimicrobial peptides and proteins (AMPs) such as hepcidin, lipocalin, defencins, etc. Also, MSCs-derived EVs are applicable in drug delivery systems, vaccine platform, and diagnostic tools to fight infectious diseases. In clinic, several challenges exist for the manufacturing clinical- and GMP-grade EVs which needs to be addressed. Further understanding of the manufacturing of EVs for clinical application, their biogenesis method as well as their optimization

\section{REFERENCES}

Abels, E. R., and Breakefield, X. O. (2016). Introduction to extracellular vesicles: biogenesis, RNA cargo selection, content, release, and uptake. Cellular Mol. Neurobiol. 36, 301-312. doi: 10.1007/s10571-016-0366-z

Addi, C. (2019). ALIX/Syntenin/Syndecan-4: An ESCRT-to-Membrane Coupling Required for Completion of Cytokinesis. Paris: Sorbonne Université.

Akbari, A., and Rezaie, J. (2020). Potential therapeutic application of mesenchymal stem cell-derived exosomes in SARS-CoV-2 pneumonia. Stem Cell Res. Ther. 11, 1-10. doi: 10.1186/s13287-020-01866-6

Akers, J. C., Gonda, D., Kim, R., Carter, B. S., and Chen, C. C. (2013). Biogenesis of extracellular vesicles (EV): exosomes, microvesicles, retrovirus-like vesicles, and apoptotic bodies. J. Neuro-Oncol. 113, 1-11. doi: 10.1007/s11060-013-1 084-8

Alcayaga-Miranda, F., Cuenca, J., and Khoury, M. (2017). Antimicrobial activity of mesenchymal stem cells: current status and new perspectives of antimicrobial peptide-based therapies. Front. Immunol. 8:339. doi: 10.3389/fimmu.2017. 00339

Alvarez, S., Suazo, C., Boltansky, A., Ursu, M., Carvajal, D., Innocenti, G., et al. (2013). Urinary exosomes as a source of kidney dysfunction biomarker in renal transplantation. Transplant. Proc. 45, 3719-3723. doi: 10.1016/j.transproceed. 2013.08.079

Antwi-Baffour, S., Malibha-Pinchbeck, M., Stratton, D., Jorfi, S., Lange, S., and Inal, J. (2020). Plasma mEV levels in Ghanain malaria patients with low parasitaemia are higher than those of healthy controls, raising the potential for parasite markers in mEVs as diagnostic targets. J. Extracellular Vesicles 9:1697124. doi: 10.1080/20013078.2019.1697124

Arslan, F., Lai, R. C., Smeets, M. B., Akeroyd, L., Choo, A., Aguor, E. N., et al. (2013). Mesenchymal stem cell-derived exosomes increase ATP levels, decrease oxidative stress and activate PI3K/Akt pathway to enhance myocardial viability and prevent adverse remodeling after myocardial ischemia/reperfusion injury. Stem Cell Res. 10, 301-312. doi: 10.1016/j.scr.2013.01.002

Athman, J. J., Wang, Y., McDonald, D. J., Boom, W. H., Harding, C. V., and Wearsch, P. A. (2015). Bacterial membrane vesicles mediate the release of mycobacterium tuberculosis lipoglycans and lipoproteins from infected macrophages. J. Immunol. (Baltimore, Md : 1950). 195, 1044-1053. doi: 10. 4049/jimmunol.1402894

Babaei, M., and Rezaie, J. (2021). Application of stem cell-derived exosomes in ischemic diseases: opportunity and limitations. J. Transl. Med. 19, 1-11. doi: 10.1186/s12967-021-02863-w method can reduce many of the challenges in using MSCsderived EVs in the clinic. Taken together, these data suggest that MSC-derived EVs could be promising therapeutic tool for the treatment of infectious diseases.

\section{AUTHOR CONTRIBUTIONS}

HK involved in drafting and editing. BS involved in drafting and figures. SR and NH-K involved in drafting. AY and $\mathrm{MH}$ involved in conceptualization, editing and proofreading. MV involved in conceptualization, reviewing and editing the draft, and final approval. All authors contributed to the article and approved the submitted version.

\section{ACKNOWLEDGMENTS}

The authors appreciate supportive colleagues in regenerative Medicine Department, Royan Institute.

Babst, M. (2011). MVB vesicle formation: ESCRT-dependent, ESCRT-independent and everything in between. Curr. Opin. Cell Biol. 23, 452-457. doi: 10.1016/j. ceb.2011.04.008

Balhuizen, M. D., Veldhuizen, E. J., and Haagsman, H. P. (2021). Outer membrane vesicle induction and isolation for vaccine development. Front. Microbiol. 12:629090. doi: 10.3389/fmicb.2021.629090

Barry, O., Praticò, D., Savani, R., and Fitzgerald, G. (1998). Modulation of monocyte-endothelial cell interaction by platelet microparticles. J. Clin. Investigat. 102, 136-144. doi: 10.1172/JCI2592

Bartolini, E., Ianni, E., Frigimelica, E., Petracca, R., Galli, G., Berlanda Scorza, F., et al. (2013). Recombinant outer membrane vesicles carrying Chlamydia muridarum HtrA induce antibodies that neutralize chlamydial infection in vitro. J. Extracellular Vesicles 2:20181. doi: 10.3402/jev.v2i0.20181

Bhatnagar, S., Shinagawa, K., Castellino, F. J., and Schorey, J. S. (2007). Exosomes released from macrophages infected with intracellular pathogens stimulate a proinflammatory response in vitro and in vivo. Blood 110, 3234-3244. doi: 10.1182/blood-2007-03-079152

Bhattarai, N., McLinden, J. H., Xiang, J., Kaufman, T. M., and Stapleton, J. T. (2015). Conserved motifs within hepatitis C virus envelope (E2) RNA and protein independently inhibit T cell activation. PLoS Pathogens 11:e1005183. doi: 10.1371/journal.ppat.1005183

Bitto, N. J., Baker, P. J., Dowling, J. K., Wray-McCann, G., De Paoli, A., Tran, L. S., et al. (2018). Membrane vesicles from Pseudomonas aeruginosa activate the noncanonical inflammasome through caspase-5 in human monocytes. Immunol. Cell Biol. 96, 1120-1130. doi: 10.1111/imcb.12190

Bitto, N. J., Chapman, R., Pidot, S., Costin, A., Lo, C., Choi, J., et al. (2017). Bacterial membrane vesicles transport their DNA cargo into host cells. Sci. Rep. 7:7072. doi: 10.1038/s41598-017-07288-4

Bobrie, A., Colombo, M., Raposo, G., and Théry, C. (2011). Exosome secretion: molecular mechanisms and roles in immune responses. Traffic 12, 1659-1668. doi: 10.1111/j.1600-0854.2011.01225.x

Böing, A. N., Van Der Pol, E., Grootemaat, A. E., Coumans, F. A., Sturk, A., and Nieuwland, R. (2014). Single-step isolation of extracellular vesicles by sizeexclusion chromatography. J. Extracellular Vesicles 3:23430. doi: 10.3402/jev. v3.23430

Bosch, S., de Beaurepaire, L., Allard, M., Mosser, M., Heichette, C., Chrétien, D., et al. (2016). Trehalose prevents aggregation of exosomes and cryodamage. Sci. Rep. 6:36162. doi: 10.1038/srep36162

Bose, S., Aggarwal, S., Singh, D. V., and Acharya, N. (2020). Extracellular vesicles: an emerging platform in gram-positive bacteria. Microb. Cell. 7:312. doi: 10 . $15698 /$ mic2020.12.737 
Brown, L., Wolf, J. M., Prados-Rosales, R., and Casadevall, A. (2015). Through the wall: extracellular vesicles in Gram-positive bacteria, mycobacteria and fungi. Nat. Rev. Microbiol. 13, 620-630. doi: 10.1038/nrmicro3480

Budoni, M., Fierabracci, A., Luciano, R., Petrini, S., Di Ciommo, V., and Muraca, M. (2013). The immunosuppressive effect of mesenchymal stromal cells on $B$ lymphocytes is mediated by membrane vesicles. Cell Transplantat. 22, 369-379. doi: $10.3727 / 096368911$ X582769b

Busatto, S., Vilanilam, G., Ticer, T., Lin, W.-L., Dickson, D. W., Shapiro, S., et al. (2018). Tangential flow filtration for highly efficient concentration of extracellular vesicles from large volumes of fluid. Cells 7:273. doi: 10.3390/ cells 7120273

Camussi, G., Deregibus, M. C., Bruno, S., Cantaluppi, V., and Biancone, L. (2010). Exosomes/microvesicles as a mechanism of cell-to-cell communication. Kidney Int. 78, 838-848. doi: $10.1038 / \mathrm{ki} .2010 .278$

Cañas, M.-A., Fábrega, M.-J., Giménez, R., Badia, J., and Baldomà, L. (2018). Outer membrane vesicles from probiotic and commensal Escherichia coli activate NOD1-Mediated immune responses in intestinal epithelial cells. Front. Microbiol. 9:498. doi: 10.3389/fmicb.2018.00498

Canton, J. (2018). Macropinocytosis: new insights into its underappreciated role in innate immune cell surveillance. Front. Immunol. 9:2286. doi: 10.3389/fimmu. 2018.02286

Caruso, S., and Poon, I. K. (2018). Apoptotic cell-derived extracellular vesicles: more than just debris. Front. Immunol. 9:1486. doi: 10.3389/fimmu.2018.01486

Chahar, H. S., Corsello, T., Kudlicki, A. S., Komaravelli, N., and Casola, A. (2018). Respiratory syncytial virus infection changes cargo composition of exosome released from airway epithelial cells. Sci. Rep. 8:387. doi: 10.1038/s41598-017$18672-5$

Chen, W., Jin, W., Hardegen, N., Lei, K.-J., Li, L., and Marinos, N. (2003). Conversion of peripheral CD4+CD25-naive T cells to CD4+ CD25+ regulatory T cells by TGF- $\beta$ induction of transcription factor Foxp3. J. Exp. Med. 198, 1875-1886. doi: 10.1084/jem.20030152

Choi, Y., Park, H., Park, H. S., and Kim, Y. K. (2017). Extracellular vesicles, a key mediator to link environmental microbiota to airway immunity. Allergy Asthma Immunol. Res. 9, 101-106. doi: 10.4168/aair.2017.9.2.101

Chronopoulos, A., and Kalluri, R. (2020). Emerging role of bacterial extracellular vesicles in cancer. Oncogene 39, 6951-6960. doi: 10.1038/s41388-020-01509-3

Cocucci, E., Racchetti, G., and Meldolesi, J. (2009). Shedding microvesicles: artefacts no more. Trends Cell Biol. 19, 43-51. doi: 10.1016/j.tcb.2008.1 1.003

Collett, G. P., Redman, C. W., Sargent, I. L., and Vatish, M. (2018). Endoplasmic reticulum stress stimulates the release of extracellular vesicles carrying dangerassociated molecular pattern (DAMP) molecules. Oncotarget 9:6707. doi: 10. 18632/oncotarget.24158

Colombo, M., Raposo, G., and Théry, C. (2014). Biogenesis, secretion, and intercellular interactions of exosomes and other extracellular vesicles. Annu. Rev. Cell Dev. Biol. 30, 255-289. doi: 10.1146/annurev-cellbio-101512-122326

Crenshaw, B. J., Gu, L., Sims, B., and Matthews, Q. L. (2018). Exosome biogenesis and biological function in response to viral infections. Open Virol. J. 12:134. doi: 10.2174/1874357901812010134

da Cruz, A. B., Maia, M. M., Pereira, I. D. S., Taniwaki, N. N., Namiyama, G. M., and Telles, J. P. M. (2020). Human extracellular vesicles and correlation with two clinical forms of toxoplasmosis. PLoS One 15:e229602. doi: 10.1371/journal. pone.0229602

Dabrowska, S., Andrzejewska, A., Janowski, M., and Lukomska, B. (2021). Immunomodulatory and regenerative effects of mesenchymal stem cells and extracellular vesicles: therapeutic outlook for inflammatory and degenerative diseases. Front. Immunol. 11:591065. doi: 10.3389/fimmu.2020.591065

de Carvalho, J. V., de Castro, R. O., da Silva, E. Z. M., Silveira, P. P., da SilvaJanuário, M. E., and Arruda, E. (2014). Nef neutralizes the ability of exosomes from CD4+ T cells to act as decoys during HIV-1 infection. PLoS One 9:e113691. doi: 10.1371/journal.pone.0113691

Deng, S., Wang, Y., Liu, S., Chen, T., Hu, Y., Zhang, G., et al. (2020). Extracellular vesicles: a potential biomarker for quick identification of infectious osteomyelitis. Front. Cell. Infect. Microbiol. 10:323. doi: 10.3389/ fcimb. 2020.00323

Dini, L., Tacconi, S., Carata, E., Tata, A., Vergallo, C., and Panzarini, E. (2020). Microvesicles and exosomes in metabolic diseases and inflammation. Cytokine Growth Factor Rev. 51, 27-39. doi: 10.1016/j.cytogfr.2019.12.008
Doyle, L. M., and Wang, M. Z. (2019). Overview of extracellular vesicles, their origin, composition, purpose, and methods for exosome isolation and analysis. Cells 8:727. doi: 10.3390/cells8070727

Duong, N., Curley, K., Brown, A., Campanelli, A., Do, M. A., Levy, D., et al. (2019). Decoy exosomes as a novel biologic reagent to antagonize inflammation. Int. J. Nanomed. 14:3413. doi: 10.2147/IJN.S196975

Elsharkasy, O. M., Nordin, J. Z., Hagey, D. W., de Jong, O. G., Schiffelers, R. M., Andaloussi, S. E. L., et al. (2020). Extracellular vesicles as drug delivery systems: why and how? Adv. Drug Delivery Rev. 159, 332-343. doi: 10.1016/j.addr.2020. 04.004

Fantappiè, L., de Santis, M., Chiarot, E., Carboni, F., Bensi, G., Jousson, O., et al. (2014). Antibody-mediated immunity induced by engineered Escherichia coli OMVs carrying heterologous antigens in their lumen. J. Extracellular Vesicles 3:24015. doi: $10.3402 /$ jev.v3.24015

Fleming, A., Sampey, G., Chung, M. C., Bailey, C., Van Hoek, M. L., Kashanchi, F., et al. (2014). The carrying pigeons of the cell: exosomes and their role in infectious diseases caused by human pathogens. Pathogens Dis. 71, 109-120. doi: 10.1111/2049-632X.12135

Frankel, E., and Audhya, A. (eds) (2018). ESCRT-dependent cargo sorting at multivesicular endosomes. Semin. Cell Dev. Biol. 74, 4-10. doi: 10.1016/j. semcdb.2017.08.020

Furuyama, N., and Sircili, M. P. (2021). Outer membrane vesicles (OMVs) produced by gram-negative bacteria: structure, functions, biogenesis, and vaccine application. BioMed. Res. Int. 2021:1490732. doi: 10.1155/2021/ 1490732

Garín, M. I., Chu, C.-C., Golshayan, D., Cernuda-Morollón, E., Wait, R., and Lechler, R. I. (2007). Galectin-1: a key effector of regulation mediated by CD4+ CD25+ T cells. Blood 109, 2058-2065. doi: 10.1182/blood-2006-04-016451

Giri, P. K., Kruh, N. A., Dobos, K. M., and Schorey, J. S. (2010). Proteomic analysis identifies highly antigenic proteins in exosomes from M. tuberculosis-infected and culture filtrate protein-treated macrophages. Proteomics 10, 3190-3202. doi: $10.1002 /$ pmic. 200900840

Golchin, A., Seyedjafari, E., and Ardeshirylajimi, A. (2020). Mesenchymal stem cell therapy for COVID-19: present or future. Stem Cell Rev. Rep. 16, 427-433. doi: 10.1007/s12015-020-09973-w

Gorringe, A. R., and Pajón, R. (2012). Bexsero: a multicomponent vaccine for prevention of meningococcal disease. Hum. Vaccines Immunother. 8, 174-183. doi: $10.4161 /$ hv. 18500

Gu, L., Meng, R., Tang, Y., Zhao, K., Liang, F., Zhang, R., et al. (2019). TollLike Receptor 4 signaling licenses the cytosolic transport of lipopolysaccharide from bacterial outer membrane vesicles. Shock 51, 256-265. doi: 10.1097/SHK. 0000000000001129

Guan, M., Chen, X., Ma, Y., Tang, L., Guan, L., Ren, X., et al. (2015). MDA-9 and GRP78 as potential diagnostic biomarkers for early detection of melanoma metastasis. Tumor Biol. 36, 2973-2982. doi: 10.1007/s13277-014-2930-9

Guo, S., Chen, J., Chen, F., Zeng, Q., Liu, W.-L., and Zhang, G. (2021). Exosomes derived from \&It;em\&gt;Fusobacterium nucleatum\&It;/em\&gt;infected colorectal cancer cells facilitate tumour metastasis by selectively carrying miR-1246/92b-3p/27a-3p and CXCL16. Gut 70:1507. doi: 10.1136/ gutjnl-2020-321187

Gurunathan, S., Kang, M.-H., Jeyaraj, M., Qasim, M., and Kim, J.-H. (2019). Review of the isolation, characterization, biological function, and multifarious therapeutic approaches of exosomes. Cells 8:307. doi: 10.3390/cells8040307

Gurunathan, S., Kang, M.-H., and Kim, J.-H. (2021). A comprehensive review on factors influences biogenesis, functions, therapeutic and clinical implications of exosomes. Int. J. Nanomed. 16:1281. doi: 10.2147/IJN.S291956

Gutiérrez-Vázquez, C., Villarroya-Beltri, C., Mittelbrunn, M., and Sánchez-Madrid, F. (2013). Transfer of extracellular vesicles during immune cell-cell interactions. Immunol. Rev. 251, 125-142. doi: 10.1111/imr.12013

György, B., Hung, M. E., Breakefield, X. O., and Leonard, J. N. (2015). Therapeutic applications of extracellular vesicles: clinical promise and open questions. Annu. Rev. Pharmacol. Toxicol. 55, 439-464. doi: 10.1146/annurev-pharmtox010814-124630

Haney, M. J., Klyachko, N. L., Zhao, Y., Gupta, R., Plotnikova, E. G., He, Z., et al. (2015). Exosomes as drug delivery vehicles for Parkinson's disease therapy. J. Controlled Release 207, 18-30. doi: 10.1016/j.jconrel.2015.03.033

Haraszti, R. A., Miller, R., Stoppato, M., Sere, Y. Y., Coles, A., Didiot, M.-C., et al. (2018). Exosomes produced from 3D cultures of MSCs by tangential 
flow filtration show higher yield and improved activity. Molecular Therapy 26, 2838-2847. doi: 10.1016/j.ymthe.2018.09.015

Harder, J., Meyer-Hoffert, U., Teran, L. M., Schwichtenberg, L., Bartels, J., Maune, S., et al. (2000). Mucoid Pseudomonas aeruginosa, TNF- $\alpha$, and IL-1 $\beta$, but Not IL-6, induce human $\beta$-defensin-2 in respiratory epithelia. Am. J. Respiratory Cell Mol. Biol. 22, 714-721. doi: 10.1165/ajrcmb.22.6.4023

Harding, C. V., Heuser, J. E., and Stahl, P. D. (2013). Exosomes: looking back three decades and into the future. J. Cell Biol. 200, 367-371. doi: 10.1083/jcb. 201212113

Heath, N., Grant, L., De Oliveira, T. M., Rowlinson, R., Osteikoetxea, X., Dekker, N., et al. (2018). Rapid isolation and enrichment of extracellular vesicle preparations using anion exchange chromatography. Sci. Rep. 8:5730. doi: 10.1038/s41598-018-24163-y

Hiemstra, T. F., Charles, P. D., Gracia, T., Hester, S. S., Gatto, L., Al-Lamki, R., et al. (2014). Human urinary exosomes as innate immune effectors. J. Am. Soc. Nephrol. 25:2017. doi: 10.1681/ASN.2013101066

Hogan, M. C., Bakeberg, J. L., Gainullin, V. G., Irazabal, M. V., Harmon, A. J., Lieske, J. C., et al. (2015). Identification of biomarkers for PKD1 using urinary exosomes. J. Am. Soc. Nephrol. 26, 1661-1670. doi: 10.1681/ASN.2014040354

Hood, J. L., San, R. S., and Wickline, S. A. (2011). Exosomes released by melanoma cells prepare sentinel lymph nodes for tumor metastasis. Cancer Res. 71, 3792-3801. doi: 10.1158/0008-5472.CAN-10-4455

Hu, G., Gong, A.-Y., Roth, A. L., Huang, B. Q., Ward, H. D., Zhu, G., et al. (2013). Release of luminal exosomes contributes to TLR4-Mediated epithelial antimicrobial defense. PLoS Pathogens 9:e1003261. doi: 10.1371/journal.ppat. 1003261

Hughes, D. T., and Sperandio, V. (2008). Inter-kingdom signalling: communication between bacteria and their hosts. Nat. Rev. Microbiol. 6, 111-120. doi: $10.1038 /$ nrmicro1836

Hui Winnie, W., Hercik, K., Belsare, S., Alugubelly, N., Clapp, B., Rinaldi, C., et al. (2018). Salmonella enterica serovar typhimurium alters the extracellular proteome of macrophages and leads to the production of proinflammatory exosomes. Infect. Immun. 86, e386-e317. doi: 10.1128/IAI.00386-17

Hyenne, V., Labouesse, M., and Goetz, J. G. (2018). The small GTPase Ral orchestrates MVB biogenesis and exosome secretion. Small GTPases 9, 445-451. doi: $10.1080 / 21541248.2016 .1251378$

Isola, A. L., and Chen, S. (2017). Extracellular vesicles: important players in immune homeostasis. Ann. Transl. Med. 5(Suppl. 1):S16. doi: 10.21037/atm. 2017.03.76

Jadli, A. S., Ballasy, N., Edalat, P., and Patel, V. B. (2020). Inside (sight) of tiny communicator: exosome biogenesis, secretion, and uptake. Mol. Cell. Biochem. 467, 77-94. doi: 10.1007/s11010-020-03703-z

Jiang, K., Yang, J., Guo, S., Zhao, G., Wu, H., and Deng, G. (2019). Peripheral circulating exosome-mediated delivery of miR-155 as a novel mechanism for acute lung inflammation. Mol. Ther. 27, 1758-1771. doi: 10.1016/j.ymthe.2019. 07.003

Kang, C.-S., Ban, M., Choi, E.-J., Moon, H.-G., Jeon, J.-S., Kim, D.-K., et al. (2013). Extracellular vesicles derived from gut microbiota, especially akkermansia muciniphila, protect the progression of dextran sulfate sodium-induced colitis. PLoS One 8:e76520. doi: 10.1371/journal.pone.0076520

Kaparakis, M., Turnbull, L., Carneiro, L., Firth, S., Coleman, H. A., Parkington, H. C., et al. (2010). Bacterial membrane vesicles deliver peptidoglycan to NOD1 in epithelial cells. Cellular Microbiol. 12, 372-385. doi: 10.1111/j.1462-5822. 2009.01404.x

Kaparakis-Liaskos, M., and Ferrero, R. L. (2015). Immune modulation by bacterial outer membrane vesicles. Nat. Rev. Immunol. 15, 375-387. doi: 10.1038/ nri3837

Keerthikumar, S., Chisanga, D., Ariyaratne, D., Al Saffar, H., Anand, S., Zhao, K., et al. (2016). ExoCarta: a web-based compendium of exosomal cargo. J. Mol. Biol. 428, 688-692. doi: 10.1016/j.jmb.2015.09.019

Keller, M. D., Ching, K. L., Liang, F.-X., Dhabaria, A., Tam, K., Ueberheide, B. M., et al. (2020). Decoy exosomes provide protection against bacterial toxins. Nature 579, 260-264. doi: 10.1038/s41586-020-2066-6

Kesimer, M., Scull, M., Brighton, B., DeMaria, G., Burns, K., O’Neal, W., et al. (2009). Characterization of exosome-like vesicles released from human tracheobronchial ciliated epithelium: a possible role in innate defense. FASEB J. 23, 1858-1868. doi: 10.1096/fj.08-119131
Kim, M. R., Hong, S. W., Choi, E. B., Lee, W. H., Kim, Y. S., Jeon, S. G., et al. (2012). Staphylococcus aureus-derived extracellular vesicles induce neutrophilic pulmonary inflammation via both Th1 and Th17 cell responses. Allergy 67, 1271-1281. doi: 10.1111/all.12001

Kim, O. Y., Park, H. T., Dinh, N. T. H., Choi, S. J., Lee, J., Kim, J. H., et al. (2017). Bacterial outer membrane vesicles suppress tumor by interferon- $\gamma$-mediated antitumor response. Nat. Commun. 8:626. doi: 10.1038/s41467-017-00729-8

Knijff-Dutmer, E., Koerts, J., Nieuwland, R., Kalsbeek-Batenburg, E. V., and Van De Laar, M. (2002). Elevated levels of platelet microparticles are associated with disease activity in rheumatoid arthritis. Arthritis Rheumatism: Off. J. Am. College Rheumatol. 46, 1498-1503. doi: 10.1002/art.10312

Krasnodembskaya, A., Song, Y., Fang, X., Gupta, N., Serikov, V., Lee, J. W., et al. (2010). Antibacterial effect of human mesenchymal stem cells is mediated in part from secretion of the antimicrobial peptide LL-37. Stem Cells 28, 2229-2238. doi: 10.1002/stem.544

Kruh-Garcia, N. A., Wolfe, L. M., Chaisson, L. H., Worodria, W. O., Nahid, P., Schorey, J. S., et al. (2014). Detection of Mycobacterium tuberculosis peptides in the exosomes of patients with active and latent $\mathrm{M}$. tuberculosis infection using MRM-MS. PLoS One 9:e103811. doi: 10.1371/journal.pone.0103811

Kumar, A., Zhang, J., and Fu-Shin, X. Y. (2006). Toll-like receptor 2-mediated expression of $\beta$-defensin-2 in human corneal epithelial cells. Microbes Infect. 8, 380-389. doi: 10.1016/j.micinf.2005.07.006

Lai, C., and Breakefield, X. (2012). Role of exosomes/microvesicles in the nervous system and use in emerging therapies. Front. Physiol. 3:228. doi: 10.3389/fphys. 2012.00228

Lässer, C., Seyed Alikhani, V., Ekström, K., Eldh, M., Torregrosa Paredes, P., Bossios, A., et al. (2011). Human saliva, plasma and breast milk exosomes contain RNA: uptake by macrophages. J. Transl. Med. 9:9. doi: 10.1186/14795876-9-9

Lee, C.-H., Im, E.-J., Moon, P.-G., and Baek, M.-C. (2018). Discovery of a diagnostic biomarker for colon cancer through proteomic profiling of small extracellular vesicles. BMC Cancer 18:1058. doi: 10.1186/s12885-018-4952-y

Lee Hannah, S. W., Boulton Ian, C., Reddin, K., Wong, H., Halliwell, D., Mandelboim, O., et al. (2007). Neisserial outer membrane vesicles bind the coinhibitory receptor carcinoembryonic antigen-related cellular adhesion molecule 1 and suppress CD4+ T lymphocyte function. Infect. Immun. 75, 4449-4455. doi: 10.1128/IAI.00222-07

Lener, T., Gimona, M., Aigner, L., Börger, V., Buzas, E., Camussi, G., et al. (2015). Applying extracellular vesicles based therapeutics in clinical trials-an ISEV position paper. J. Extracellular Vesicles 4:30087. doi: 10.3402/jev.v4.30087

Li, L., Cheng, Y., Emrich, S., and Schorey, J. (2018). Activation of endothelial cells by extracellular vesicles derived from Mycobacterium tuberculosis infected macrophages or mice. PLoS One 13:e198337. doi: 10.1371/journal.pone. 0198337

Li, X., Corbett, A. L., Taatizadeh, E., Tasnim, N., Little, J. P., Garnis, C., et al. (2019). Challenges and opportunities in exosome research-Perspectives from biology, engineering, and cancer therapy. APL Bioeng. 3:011503. doi: 10.1063/1.5087122

Li, X., Duan, D., Yang, J., Wang, P., Han, B., Zhao, L., et al. (2016). The expression of human $\beta$-defensins (hBD-1, hBD-2, hBD-3, hBD-4) in gingival epithelia. Arch. Oral Biol. 66, 15-21. doi: 10.1016/j.archoralbio.2016.01.012

Lindenbergh, M. F. S., and Stoorvogel, W. (2018). Antigen presentation by extracellular vesicles from professional antigen-presenting cells. Annu. Rev. Immunol. 36, 435-459. doi: 10.1146/annurev-immunol-041015-055700

Lisco, A., Vanpouille, C., and Margolis, L. (2009). War and peace between microbes: HIV-1 interactions with coinfecting viruses. Cell Host Microbe 6, 403-408. doi: 10.1016/j.chom.2009.10.010

Liu, S., da Cunha Andre, P., Rezende Rafael, M., Cialic, R., Wei, Z., and Bry, L. (2016). The host shapes the gut microbiota via fecal MicroRNA. Cell Host Microbe 19, 32-43. doi: 10.1016/j.chom.2015.12.005

Liu, T., Zhang, Q., Zhang, J., Li, C., Miao, Y.-R., Lei, Q., et al. (2019). EVmiRNA: a database of miRNA profiling in extracellular vesicles. Nucleic Acids Res. 47, D89-D93. doi: 10.1093/nar/gky985

Lombardi, L., Maisetta, G., Batoni, G., and Tavanti, A. (2015). Insights into the antimicrobial properties of hepcidins: advantages and drawbacks as potential therapeutic agents. Molecules 20, 6319-6341. doi: 10.3390/molecules20046319

Lv, L., Li, C., Zhang, X., Ding, N., Cao, T., Jia, X., et al. (2017). RNA profiling analysis of the serum exosomes derived from patients with active and latent 
Mycobacterium tuberculosis infection. Front. Microbiol. 8:1051. doi: 10.3389/ fmicb.2017.01051

Lynch, S. F., and Ludlam, C. A. (2007). Plasma microparticles and vascular disorders. Br. J. Haematol. 137, 36-48. doi: 10.1111/j.1365-2141.2007.06514.x

Lyu, L., Zhang, X., Li, C., Yang, T., Wang, J., Pan, L., et al. (2019). Small RNA profiles of serum exosomes derived from individuals with latent and active tuberculosis. Front. Microbiol. 10:1174. doi: 10.3389/fmicb.2019.01174

Maemura, T., Fukuyama, S., and Kawaoka, Y. (2020). High levels of miR-483-3p are present in serum exosomes upon infection of mice with highly pathogenic avian influenza virus. Front. Microbiol. 11:144. doi: 10.3389/fmicb.2020.00144

Marcoux, G., Magron, A., Sut, C., Laroche, A., Laradi, S., and Hamzeh-Cognasse, H. (2019). Platelet-derived extracellular vesicles convey mitochondrial DAMPs in platelet concentrates and their levels are associated with adverse reactions. Transfusion 59, 2403-2414. doi: 10.1111/trf.15300

Mardpour, S., Hassani, S. N., Mardpour, S., Sayahpour, F., Vosough, M., Ai, J., et al. (2018). Extracellular vesicles derived from human embryonic stem cell-MSCs ameliorate cirrhosis in thioacetamide-induced chronic liver injury. J. Cellular Physiol. 233, 9330-9344. doi: 10.1002/jcp.26413

Martins, SDT, and Alves, L. R. (2020). Extracellular vesicles in viral infections: two sides of the same coin? Front. Cell. Infecti. Microbiol. 10:593170. doi: $10.3389 /$ fcimb. 2020.593170

Mathivanan, S., Ji, H., and Simpson, R. J. (2010). Exosomes: extracellular organelles important in intercellular communication. J. Proteomics 73, 1907-1920. doi: 10.1016/j.jprot.2010.06.006

Matthews, R. (1975). A classification of virus groups based on the size of the particle in relation to genome size. J. Gen. Virol. 27, 135-149. doi: 10.1099/0022-131727-2-135

Mehanny, M., Koch, M., Lehr, C.-M., and Fuhrmann, G. (2020). Streptococcal extracellular membrane vesicles are rapidly internalized by immune cells and alter their cytokine release. Front. Immunol. 11:80. doi: 10.3389/fimmu.2020. 00080

Melo, S. A., Luecke, L. B., Kahlert, C., Fernandez, A. F., Gammon, S. T., Kaye, J., et al. (2015). Glypican-1 identifies cancer exosomes and detects early pancreatic cancer. Nature 523, 177-182. doi: 10.1038/nature14581

Min, L., Zhu, S., Chen, L., Liu, X., Wei, R., Zhao, L., et al. (2019). Evaluation of circulating small extracellular vesicles derived miRNAs as biomarkers of early colon cancer: a comparison with plasma total miRNAs. J. Extracellular Vesicles 8:1643670. doi: $10.1080 / 20013078.2019 .1643670$

Mishra, R., Lata, S., Ali, A., and Banerjea, A. C. (2019). Dengue haemorrhagic fever: a job done via exosomes? Emerg. Microbes Infect. 8, 1626-1635. doi: $10.1080 / 22221751.2019 .1685913$

Mobarak, H., Heidarpour, M., Rahbarghazi, R., Nouri, M., and Mahdipour, M. (2021). Amniotic fluid-derived exosomes improved spermatogenesis in a rat model of azoospermia. Life Sci. 274:119336. doi: 10.1016/j.lfs.2021.119336

Mokarizadeh, A., Delirezh, N., Morshedi, A., Mosayebi, G., Farshid, A.-A., and Mardani, K. (2012). Microvesicles derived from mesenchymal stem cells: potent organelles for induction of tolerogenic signaling. Immunol. Lett. 147, 47-54. doi: 10.1016/j.imlet.2012.06.001

Montaner-Tarbes, S., Novell, E., Tarancón, V., Borrás, F. E., Montoya, M., Fraile, L., et al. (2018). Targeted-pig trial on safety and immunogenicity of serum-derived extracellular vesicles enriched fractions obtained from Porcine Respiratory and Reproductive virus infections. Sci. Rep. 8:17487. doi: 10.1038/s41598-01836141-5

Munich, S., Sobo-Vujanovic, A., Buchser, W. J., Beer-Stolz, D., and Vujanovic, N. L. (2012). Dendritic cell exosomes directly kill tumor cells and activate natural killer cells via TNF superfamily ligands. Oncoimmunology 1, 1074-1083. doi: $10.4161 /$ onci.20897

Muraca, M., Putignani, L., Fierabracci, A., Teti, A., and Perilongo, G. (2015). Gut microbiota-derived outer membrane vesicles: under-recognized major players in health and disease? Discov. Med. 19, 343-348.

Nanbo, A., Kawanishi, E., Yoshida, R., and Yoshiyama, H. (2013). Exosomes derived from Epstein-Barr virus-infected cells are internalized via caveoladependent endocytosis and promote phenotypic modulation in target cells. J. Virol. 87, 10334-10347. doi: 10.1128/JVI.01310-13

Narayanan, A., Iordanskiy, S., Das, R., Van Duyne, R., Santos, S., Jaworski, E., et al. (2013). Exosomes derived from HIV-1-infected cells contain trans-activation response element RNA*. J. Biol. Chem. 288, 20014-20033. doi: 10.1074/jbc. M112.438895
Nassar, W., El-Ansary, M., Sabry, D., Mostafa, M. A., Fayad, T., Kotb, E., et al. (2016). Umbilical cord mesenchymal stem cells derived extracellular vesicles can safely ameliorate the progression of chronic kidney diseases. Biomater. Res. 20, 1-11. doi: 10.1186/s40824-016-0068-0

Natasha, G., Gundogan, B., Tan, A., Farhatnia, Y., Wu, W., Rajadas, J., et al. (2014). Exosomes as immunotheranostic nanoparticles. Clin. Therapeutics 36, 820-829. doi: 10.1016/j.clinthera.2014.04.019

Nikfarjam, S., Rezaie, J., Kashanchi, F., and Jafari, R. (2020). Dexosomes as a cellfree vaccine for cancer immunotherapy. J. Exp. Clin. Cancer Res. 39, 1-20. doi: 10.1186/s13046-020-01781-x

Nolte-'t Hoen, E., Cremer, T., Gallo, R. C., and Margolis, L. B. (2016). Extracellular vesicles and viruses: are they close relatives? Proc. Natl. Acad. Sci. U.S.A. 113, 9155-9161. doi: 10.1073/pnas.1605146113

Obata, Y., Kita, S., Koyama, Y., Fukuda, S., Takeda, H., Takahashi, M., et al. (2018). Adiponectin/T-cadherin system enhances exosome biogenesis and decreases cellular ceramides by exosomal release. JCI Insight 3:e99680. doi: 10.1172/jci. insight. 99680

Oksvold, M. P., Neurauter, A., and Pedersen, K. W. (2015). Magnetic bead-based isolation of exosomes. Methods Mol. Biol. 1218, 465-481. doi: 10.1007/978-14939-1538-5_27

Osteikoetxea, X., Balogh, A., Szabó-Taylor, K., Németh, A., Szabó, T. G., Pálóczi, K., et al. (2015). Improved characterization of EV preparations based on protein to lipid ratio and lipid properties. PLoS One 10:e0121184. doi: 10.1371/journal. pone. 0121184

Otrokocsi, L., Kittel, A., and bet Ligeti, E. (2014). Effect of storage on physical and functional properties of extracellular vesicles derived from neutrophilic granulocytes. J. Extracellular Vesicles 3:25465. doi: 10.3402/jev.v3.2 5465

Pachler, K., Lener, T., Streif, D., Dunai, Z. A., Desgeorges, A., Feichtner, M., et al. (2017b). A Good Manufacturing Practice-grade standard protocol for exclusively human mesenchymal stromal cell-derived extracellular vesicles. Cytotherapy 19, 458-472. doi: 10.1016/j.jcyt.2017.01.001

Pachler, K., Ketterl, N., Desgeorges, A., Dunai, Z. A., Laner-Plamberger, S., Streif, D., et al. (2017a). An in vitro potency assay for monitoring the immunomodulatory potential of stromal cell-derived extracellular vesicles. Int. J. Mol. Sci. 18:1413. doi: 10.3390/ijms18071413

Palmirotta, R., Lovero, D., Cafforio, P., Felici, C., Mannavola, F., Pellè, E., et al. (2018). Liquid biopsy of cancer: a multimodal diagnostic tool in clinical oncology. Therapeutic Adv. Med. Oncol. 10:1758835918794630. doi: 10.1177/ 1758835918794630

Pan, B.-T., and Johnstone, R. M. (1983). Fate of the transferrin receptor during maturation of sheep reticulocytes in vitro: selective externalization of the receptor. Cell 33, 967-978. doi: 10.1016/0092-8674(83)90040-5

Pathan, M., Fonseka, P., Chitti, S. V., Kang, T., Sanwlani, R., Van Deun, J., et al. (2019). Vesiclepedia 2019: a compendium of RNA, proteins, lipids and metabolites in extracellular vesicles. Nucleic Acids Res. 47, D516-D519. doi: 10.1093/nar/gky1029

Peek, R. M., and Blaser, M. J. (2002). Helicobacter pylori and gastrointestinal tract adenocarcinomas. Nat. Rev. Cancer 2, 28-37. doi: 10.1038/nrc703

Peinado, H., Alečković, M., Lavotshkin, S., Matei, I., Costa-Silva, B., MorenoBueno, G., et al. (2012). Melanoma exosomes educate bone marrow progenitor cells toward a pro-metastatic phenotype through MET. Nat. Med. 18, 883-891. doi: $10.1038 / \mathrm{nm} .2753$

Poon, I. K., Lucas, C. D., Rossi, A. G., and Ravichandran, K. S. (2014). Apoptotic cell clearance: basic biology and therapeutic potential. Nat. Rev. Immunol. 14, 166-180. doi: $10.1038 /$ nri3607

Pournaghi, M., Khodavirdilou, R., Saadatlou, M. A. E., Nasimi, F. S., Yousefi, S., Mobarak, H., et al. (2021). Effect of melatonin on exosomal dynamics in bovine cumulus cells. Process Biochem. 106, 78-87. doi: 10.1016/j.procbio.2021.0 3.008

Prados-Rosales, R., Baena, A., Martinez, L. R., Luque-Garcia, J., Kalscheuer, R., Veeraraghavan, U., et al. (2011). Mycobacteria release active membrane vesicles that modulate immune responses in a TLR2-dependent manner in mice. J. Clin. Investigat. 121, 1471-1483. doi: 10.1172/JCI44261

Puissant, B., Barreau, C., Bourin, P., Clavel, C., Corre, J., Bousquet, C., et al. (2005). Immunomodulatory effect of human adipose tissue-derived adult stem cells: comparison with bone marrow mesenchymal stem cells. Br. J. Haematol. 129, 118-129. doi: 10.1111/j.1365-2141.2005.05409.x 
Quah, B. J., and O'neill, H. C. (2007). Mycoplasma contaminants present in exosome preparations induce polyclonal B cell responses. J. Leukocyte Biol. 82, 1070-1082. doi: 10.1189/jlb.0507277

Rabinovich, G., Alonso, C., Sotomayor, C., Durand, S., Bocco, J., and Riera, C. (2000). Molecular mechanisms implicated in galectin-1-induced apoptosis: activation of the AP-1 transcription factor and downregulation of Bcl-2. Cell Death Diff. 7, 747-753. doi: 10.1038/sj.cdd.4400708

Raghav, A., Tripathi, P., Mishra, B. K., Jeong, G.-B., Banday, S., Gautam, K. A., et al. (2021). Mesenchymal stromal cell-derived tailored exosomes treat bacteriaassociated diabetes foot ulcers: a customized approach from bench to bed. Front. Microbiol. 12:712588. doi: 10.3389/fmicb.2021.712588

Rak, J. (ed.) (2010). Microparticles in Cancer. Seminars in Thrombosis and Hemostasis. New York, NY: Thieme Medical Publishers. doi: 10.1055/s-00301267043

Raposo, G., Nijman, H. W., Stoorvogel, W., Liejendekker, R., Harding, C. V., Melief, C. J., et al. (1996). B lymphocytes secrete antigen-presenting vesicles. J. Exp. Med. 183, 1161-1172. doi: 10.1084/jem.183.3.1161

Raposo, G., and Stoorvogel, W. (2013). Extracellular vesicles: exosomes, microvesicles, and friends. J. Cell Biol. 200, 373-383. doi: 10.1083/jcb. 201211138

Ren, G., Zhang, L., Zhao, X., Xu, G., Zhang, Y., Roberts, A. I., et al. (2008). Mesenchymal stem cell-mediated immunosuppression occurs via concerted action of chemokines and nitric oxide. Cell Stem Cell. 2, 141-150. doi: 10.1016/ j.stem.2007.11.014

Rezaie, J., Aslan, C., Ahmadi, M., Zolbanin, N. M., Kashanchi, F., and Jafari, R. (2021). The versatile role of exosomes in human retroviral infections: from immunopathogenesis to clinical application. Cell Biosci. 11, 1-15. doi: 10.1186/ s13578-021-00537-0

Rezasoltani, S., Hatami, B., Yadegar, A., Asadzadeh Aghdaei, H., and Zali, M. R. (2020a). How patients with chronic liver diseases succeed to deal with COVID19? Front. Med. 7:398. doi: 10.3389/fmed.2020.00398

Rezasoltani, S., Yadegar, A., Hatami, B., Asadzadeh Aghdaei, H., and Zali, M. R. (2020b). Antimicrobial resistance as a hidden menace lurking behind the COVID-19 outbreak: the global impacts of too much hygiene on AMR. Front. Microbiol. 11:590683. doi: 10.3389/fmicb.2020.590683

Riley, D. R., Sieber, K. B., Robinson, K. M., White, J. R., Ganesan, A., Nourbakhsh, S., et al. (2013). Bacteria-human somatic cell lateral gene transfer is enriched in cancer samples. PLoS Computat. Biol. 9:e1003107. doi: 10.1371/journal.pcbi. 1003107

Roberts, C. T., and Kurre, P. (2013). Vesicle trafficking and RNA transfer add complexity and connectivity to cell-cell communication. Cancer Res. 73:3200. doi: 10.1158/0008-5472.CAN-13-0265

Rodrigues, M., Fan, J., Lyon, C., Wan, M., and Hu, Y. (2018). Role of extracellular vesicles in viral and bacterial infections: pathogenesis, diagnostics, and therapeutics. Theranostics 8:2709. doi: 10.7150/thno.20576

Russell, A. L., Lefavor, R., Durand, N., Glover, L., and Zubair, A. C. (2018). Modifiers of mesenchymal stem cell quantity and quality. Transfusion 58, 1434-1440. doi: 10.1111/trf.14597

Saleh, A. F., Lázaro-Ibáñez, E., Forsgard, M. A.-M., Shatnyeva, O., Osteikoetxea, X., Karlsson, F., et al. (2019). Extracellular vesicles induce minimal hepatotoxicity and immunogenicity. Nanoscale 11, 6990-7001. doi: 10.1039/C8NR08720B

Salimi, L., Akbari, A., Jabbari, N., Mojarad, B., Vahhabi, A., Szafert, S., et al. (2020). Synergies in exosomes and autophagy pathways for cellular homeostasis and metastasis of tumor cells. Cell Biosci. 10, 1-18. doi: 10.1186/s13578-020-00426$\mathrm{y}$

Sandra Tjabringa, G., Rabe, K. F., and Hiemstra, P. S. (2005). The human cathelicidin LL-37: a multifunctional peptide involved in infection and inflammation in the lung. Pulmonary Pharmacol. Therapeutics 18, 321-327. doi: 10.1016/j.pupt.2005.01.001

Schiller, M., Bekeredjian-Ding, I., Heyder, P., Blank, N., Ho, A. D., and Lorenz, H.M. (2008). Autoantigens are translocated into small apoptotic bodies during early stages of apoptosis. Cell Death Diff. 15, 183-191. doi: 10.1038/sj.cdd. 4402239

Schroten, H., Spors, B., Hucke, C., Stins, M., Kim, K., Adam, R., et al. (2001). Potential role of human brain microvascular endothelial cells in the pathogenesis of brain abscess: inhibition of Staphylococcus aureus by activation of indoleamine 2, 3-dioxygenase. Neuropediatrics 32, 206-210. doi: 10.1055/s2001-17375
Sedgwick, A. E., and D'Souza-Schorey, C. (2018). The biology of extracellular microvesicles. Traffic 19, 319-327. doi: 10.1111/tra.12558

Seo, Y., Kim, H.-S., and Hong, I.-S. (2019). Stem cell-derived extracellular vesicles as immunomodulatory therapeutics. Stem Cells Int. 2019:5126156. doi: 10. $1155 / 2019 / 5126156$

Seyfi, R., Kahaki, F. A., Ebrahimi, T., Montazersaheb, S., Eyvazi, S., Babaeipour, V., et al. (2020). Antimicrobial peptides (AMPs): roles, functions and mechanism of action. Int. J. Peptide Res. Therapeutics 26, 1451-1463. doi: 10.1007/s10989019-09946-9

Shah, B., Sullivan, C. J., Lonergan, N. E., Stanley, S., Soult, M. C., and Britt, L. D. (2012). Circulating bacterial membrane vesicles cause sepsis in rats. Shock 37, 621-628. doi: 10.1097/SHK.0b013e318250de5d

Sharpe Samantha, W., Kuehn Meta, J., Mason Kevin, M., and Weiser, J. N. (2011). Elicitation of epithelial cell-derived immune effectors by outer membrane vesicles of nontypeable Haemophilus influenzae. Infect. Immun. 79, 4361-4369. doi: 10.1128/IAI.05332-11

Shelke, G. V., Lässer, C., Gho, Y. S., and Lötvall, J. (2014). Importance of exosome depletion protocols to eliminate functional and RNA-containing extracellular vesicles from fetal bovine serum. J. Extracellular Vesicles 3:24783. doi: 10.3402/ jev.v3.24783

Shen, Y., Torchia Maria Letizia, G., Lawson Gregory, W., Karp Christopher, L., Ashwell Jonathan, D., and Mazmanian Sarkis, K. (2012). Outer membrane vesicles of a human commensal mediate immune regulation and disease protection. Cell Host Microbe 12, 509-520. doi: 10.1016/j.chom.2012.0 8.004

Shkair, L., Garanina, E. E., Stott, R. J., Foster, T. L., Rizvanov, A. A., and Khaiboullina, S. F. (2021). Membrane microvesicles as potential vaccine candidates. Int. J. Mol. Sci. 22:1142. doi: 10.3390/ijms22031142

Shpichka, A., Bikmulina, P., Peshkova, M., Heydari, Z., Kosheleva, N., Vosough, M., et al. (2021). Organoids in modelling infectious diseases. Drug Discov. Today (in press). doi: $10.1016 /$ j.drudis.2021.08.005

Simons, M., and Raposo, G. (2009). Exosomes-vesicular carriers for intercellular communication. Curr. Opin. Cell Biol. 21, 575-581. doi: 10.1016/j.ceb.2009.03. 007

Sluijter, J. P., Verhage, V., Deddens, J. C., van den Akker, F., and Doevendans, P. A. (2014). Microvesicles and exosomes for intracardiac communication. Cardiovasc. Res. 102, 302-311. doi: 10.1093/cvr/cvu022

Spencer, N., and Yeruva, L. (2021). Role of bacterial infections in extracellular vesicles release and impact on immune response. Biomed. J. 44, 157-164. doi: 10.1016/j.bj.2020.05.006

Street, J., Koritzinsky, E., Glispie, D., Star, R., and Yuen, P. (2017). Urine exosomes: an emerging trove of biomarkers. Adv. Clin. Chem. 78, 103-122. doi: 10.1016/ bs.acc.2016.07.003

Street, J. M., Barran, P. E., Mackay, C. L., Weidt, S., Balmforth, C., Walsh, T. S., et al. (2012). Identification and proteomic profiling of exosomes in human cerebrospinal fluid. J. Transl. Med. 10:5. doi: 10.1186/1479-5876-10-5

Sun, X., Shan, A., Wei, Z., and Xu, B. (2018). Intravenous mesenchymal stem cell-derived exosomes ameliorate myocardial inflammation in the dilated cardiomyopathy. Biochem. Biophys. Res. Commun. 503, 2611-2618. doi: 10. 1016/j.bbrc.2018.08.012

Sung, D. K., Chang, Y. S., Sung, S. I., Yoo, H. S., Ahn, S. Y., and Park, W. S. (2016). Antibacterial effect of mesenchymal stem cells against Escherichia coli is mediated by secretion of beta-defensin- 2 via toll-like receptor 4 signalling. Cell. Microbiol. 18, 424-436. doi: 10.1111/cmi.12522

Tamura, R., Uemoto, S., and Tabata, Y. (2016). Immunosuppressive effect of mesenchymal stem cell-derived exosomes on a concanavalin A-induced liver injury model. Inflamm. Regenerat. 36, 1-11. doi: 10.1186/s41232-016-0030-5

Tauro, B. J., Greening, D. W., Mathias, R. A., Ji, H., Mathivanan, S., Scott, A. M., et al. (2012). Comparison of ultracentrifugation, density gradient separation, and immunoaffinity capture methods for isolating human colon cancer cell line LIM1863-derived exosomes. Methods 56, 293-304. doi: 10.1016/j.ymeth.2012. 01.002

Thay, B., Damm, A., Kufer, T. A., Wai, S. N., and Oscarsson, J. (2014). Aggregatibacter actinomycetemcomitans outer membrane vesicles are internalized in human host cells and trigger NOD1- and NOD2-dependent NF-kB activation. Infect. Immun. 82, 4034-4046. doi: 10.1128/IAI.01980-14

Théry, C., Amigorena, S., Raposo, G., and Clayton, A. (2006). Isolation and characterization of exosomes from cell culture supernatants and biological 
fluids. Curr. Protocols Cell Biol. 3:Unit 3.22. doi: 10.1002/0471143030. cb0322s30

Théry, C., Boussac, M., Véron, P., Ricciardi-Castagnoli, P., Raposo, G., Garin, J., et al. (2001). Proteomic analysis of dendritic cell-derived exosomes: a secreted subcellular compartment distinct from apoptotic vesicles. J. Immunol. 166, 7309-7318. doi: 10.4049/jimmunol.166.12.7309

Théry, C., Witwer, K. W., Aikawa, E., Alcaraz, M. J., Anderson, J. D., Andriantsitohaina, R., et al. (2018). Minimal information for studies of extracellular vesicles 2018 (MISEV2018): a position statement of the International Society for Extracellular Vesicles and update of the MISEV2014 guidelines. J. Extracellular Vesicles 7:1535750. doi: 10.1080/20013078.2018. 1535750

Timár, C. I., Lõrincz, A. M., Csépányi-Kömi, R., Vályi-Nagy, A., Nagy, G., and Buzás, E. I. (2013). Antibacterial effect of microvesicles released from human neutrophilic granulocytes. Blood J. Am. Soc. Hematol. 121, 510-518. doi: 10. 1182/blood-2012-05-431114

Toyofuku, M., Nomura, N., and Eberl, L. (2019). Types and origins of bacterial membrane vesicles. Nat. Rev. Microbiol. 17, 13-24. doi: 10.1038/s41579-018$0112-2$

Tsatsaronis, J. A., Franch-Arroyo, S., Resch, U., and Charpentier, E. (2018). Extracellular vesicle RNA: a universal mediator of microbial communication? Trends Microbiol. 26, 401-410. doi: 10.1016/j.tim.2018.02.009

Tulkens, J., De Wever, O., and Hendrix, A. (2020). Analyzing bacterial extracellular vesicles in human body fluids by orthogonal biophysical separation and biochemical characterization. Nat. Protocols 15, 40-67. doi: 10.1038/s41596019-0236-5

Urbanelli, L., Buratta, S., Tancini, B., Sagini, K., Delo, F., Porcellati, S., et al. (2019). The role of extracellular vesicles in viral infection and transmission. Vaccines 7:102. doi: $10.3390 /$ vaccines 7030102

Van Niel, G., Porto-Carreiro, I., Simoes, S., and Raposo, G. (2006). Exosomes: a common pathway for a specialized function. J. Biochem. 140, 13-21. doi: $10.1093 / \mathrm{jb} / \mathrm{mvj} 128$

Van Niel, G., Raposo, G., Candalh, C., Boussac, M., Hershberg, R., and CerfBensussan, N. (2001). Intestinal epithelial cells secrete exosome\&\#x2013;like vesicles. Gastroenterology 121, 337-349. doi: 10.1053/gast.2001.26263

Velandia-Romero, M. L., Calderón-Peláez, M. A., Balbás-Tepedino, A., MárquezOrtiz, R. A., Madroñero, L. J., Barreto Prieto, A., et al. (2020). Extracellular vesicles of U937 macrophage cell line infected with DENV-2 induce activation in endothelial cells EA.hy926. PLoS One 15:e0227030. doi: 10.1371/journal. pone. 0227030

Wang, C., Wang, Y., Shi, X., Tang, X., Cheng, W., Wang, X., et al. (2019). The TRAPs from microglial vesicles protect against listeria infection in the CNS. Front. Cell. Neurosci. 13:199. doi: 10.3389/fncel.2019.00199

Wang, J., Deng, Z., Wang, Z., Wu, J., Gu, T., Jiang, Y., et al. (2016). MicroRNA155 in exosomes secreted from Helicobacter pylori infection macrophages immunomodulates inflammatory response. Am. J. Transl. Res. 8:3700.

Wang, Q., Li, S., Tang, X., Liang, L., Wang, F., and Du, H. (2019). Lipocalin 2 protects against Escherichia coli infection by modulating neutrophil and macrophage function. Front. Immunol. 10:2594. doi: 10.3389/fimmu.2019. 02594

Webber, J., and Clayton, A. (2013). How pure are your vesicles? J. Extracellular Vesicles 2:19861. doi: 10.3402/jev.v2i0.19861

Wei, W., Ao, Q., Wang, X., Cao, Y., Liu, Y., Zheng, S. G., et al. (2021). Mesenchymal stem cell-derived exosomes: a promising biological tool in nanomedicine. Front. Pharmacol. 11:590470. doi: 10.3389/fphar.2020.590470

Wei, Z., Batagov, A. O., Carter, D. R., and Krichevsky, A. M. (2016). Fetal bovine serum RNA interferes with the cell culture derived extracellular RNA. Sci. Rep. 6:31175. doi: $10.1038 /$ srep31175

White, J. R., Dauros-Singorenko, P., Hong, J., Vanholsbeeck, F., Phillips, A., and Swift, S. (2021). The complex, bidirectional role of extracellular vesicles in infection. Biochem. Soc. Transact. 49, 881-891. doi: 10.1042/BST20200788

Wiest, E. F., and Zubair, A. C. (2020). Challenges of manufacturing mesenchymal stromal cell-derived extracellular vesicles in regenerative medicine. Cytotherapy 22, 606-612. doi: 10.1016/j.jcyt.2020.04.040

Willis, G. R., Fernandez-Gonzalez, A., Anastas, J., Vitali, S. H., Liu, X., Ericsson, M., et al. (2018). Mesenchymal stromal cell exosomes ameliorate experimental bronchopulmonary dysplasia and restore lung function through macrophage immunomodulation. Am. J. Respiratory Crit. Care Med. 197, 104-116. doi: 10.1164/rccm.201705-0925OC

Winau, F., Weber, S., Sad, S., De Diego, J., Hoops, S. L., Breiden, B., et al. (2006). Apoptotic vesicles crossprime CD8 $\mathrm{T}$ cells and protect against tuberculosis. Immunity 24, 105-117. doi: 10.1016/j.immuni.2005.12.001

Witwer, K. W., Buzás, E. I., Bemis, L. T., Bora, A., Lässer, C., Lötvall, J., et al. (2013). Standardization of sample collection, isolation and analysis methods in extracellular vesicle research. J. Extracellular Vesicles 2:20360. doi: 10.3402/jev. v2i0.20360

Wolf, P. (1967). The nature and significance of platelet products in human plasma. Br. J. Haematol. 13, 269-288. doi: 10.1111/j.1365-2141.1967.tb08741.x

Woo, J., Sharma, S., and Gimzewski, J. (2016). The role of isolation methods on a nanoscale surface structure and its effect on the size of exosomes. J. Circulat. Biomarkers 5:11. doi: 10.5772/64148

Yáñez-Mó, M., Siljander, P. R.-M., Andreu, Z., Bedina Zavec, A., Borràs, F. E., Buzas, E. I., et al. (2015). Biological properties of extracellular vesicles and their physiological functions. J. Extracellular Vesicles 4:27066. doi: 10.3402/jev.v4. 27066

Yang, R., Liu, Y., Kelk, P., Qu, C., Akiyama, K., Chen, C., et al. (2013). A subset of IL-17+ mesenchymal stem cells possesses anti-Candida albicans effect. Cell Res. 23, 107-121. doi: 10.1038/cr.2012.179

Yu, Y. J., Wang, X. H., and Fan, G. C. (2018). Versatile effects of bacterium-released membrane vesicles on mammalian cells and infectious/inflammatory diseases. Acta Pharmacol. Sin. 39, 514-533. doi: 10.1038/aps.2017.82

Zhang, H.-G., and Grizzle, W. E. (2011). Exosomes and cancer: a newly described pathway of immune suppression. Clin. Cancer Res. 17, 959-964. doi: 10.1158/ 1078-0432.CCR-10-1489

Zhang, Q., Higginbotham, J. N., Jeppesen, D. K., Yang, Y.-P., Li, W., McKinley, E. T., et al. (2019). Transfer of functional cargo in exomeres. Cell Rep. 27, 940.e6-954.e6. doi: 10.1016/j.celrep.2019.01.009

Zhang, Y.-K., Zhang, Q., Wang, Y.-L., Zhang, W.-Y., Hu, H.-Q., Wu, H.-Y., et al. (2021). A Comparison study of age and colorectal cancer-related gut bacteria. Front. Cell. Infect. Microbiol. 11:606490. doi: 10.3389/fcimb.2021.606490

Zhao, K., Deng, X., He, C., Yue, B., and Wu, M. (2013). Pseudomonas aeruginosa outer membrane vesicles modulate host immune responses by targeting the toll-like receptor 4 signaling pathway. Infect. Immun. 81, 4509-4518. doi: 10.1128/IAI.01008-13

Zhou, H., Kajiyama, H., Tsuji, T., Hu, X., Leelahavanichkul, A., Vento, S., et al. (2013). Urinary exosomal Wilms' tumor-1 as a potential biomarker for podocyte injury. Am. J. Physiol.-Renal Physiol. 305, F553-F559. doi: 10.1152/ ajprenal.00056.2013

Zhou, J., Li, Y.-S., Nguyen, P., Wang, K.-C., Weiss, A., Kuo, Y.-C., et al. (2013). Regulation of vascular smooth muscle cell turnover by endothelial cell-secreted microRNA-126: role of shear stress. Circulation Res. 113, 40-51. doi: 10.1161/ CIRCRESAHA.113.280883

Zitvogel, L., Kepp, O., and Kroemer, G. (2010). Decoding cell death signals in inflammation and immunity. Cell 140, 798-804. doi: 10.1016/j.cell.2010.02.015

Conflict of Interest: The authors declare that the research was conducted in the absence of any commercial or financial relationships that could be construed as a potential conflict of interest.

Publisher's Note: All claims expressed in this article are solely those of the authors and do not necessarily represent those of their affiliated organizations, or those of the publisher, the editors and the reviewers. Any product that may be evaluated in this article, or claim that may be made by its manufacturer, is not guaranteed or endorsed by the publisher.

Copyright $\odot 2021$ Keshavarz Alikhani, Shokoohian, Rezasoltani, Hossein-khannazer, Yadegar, Hassan and Vosough. This is an open-access article distributed under the terms of the Creative Commons Attribution License (CC BY). The use, distribution or reproduction in other forums is permitted, provided the original author(s) and the copyright owner(s) are credited and that the original publication in this journal is cited, in accordance with accepted academic practice. No use, distribution or reproduction is permitted which does not comply with these terms. 